Subscriber access provided by Universidad de Alicante

\title{
Applied Chemistry
}

\section{Olefin Purification and Selective Hydrogenation of Alkynes with Low Loaded Pd Nanoparticle Catalysts}

Misael Cordoba, Fernando Coloma-Pascual, Mónica Esther Quiroga, and Cecilia Rosa Rosa Lederhos

Ind. Eng. Chem. Res., Just Accepted Manuscript • DOI: 10.1021/acs.iecr.9b02081 • Publication Date (Web): 16 Aug 2019

Downloaded from pubs.acs.org on August 28, 2019

\section{Just Accepted}

"Just Accepted" manuscripts have been peer-reviewed and accepted for publication. They are posted online prior to technical editing, formatting for publication and author proofing. The American Chemical Society provides "Just Accepted" as a service to the research community to expedite the dissemination of scientific material as soon as possible after acceptance. "Just Accepted" manuscripts appear in full in PDF format accompanied by an HTML abstract. "Just Accepted" manuscripts have been fully peer reviewed, but should not be considered the official version of record. They are citable by the Digital Object Identifier (DOI®). "Just Accepted" is an optional service offered to authors. Therefore, the "Just Accepted" Web site may not include all articles that will be published in the journal. After a manuscript is technically edited and formatted, it will be removed from the "Just Accepted" Web site and published as an ASAP article. Note that technical editing may introduce minor changes to the manuscript text and/or graphics which could affect content, and all legal disclaimers and ethical guidelines that apply to the journal pertain. ACS cannot be held responsible for errors or consequences arising from the use of information contained in these "Just Accepted" manuscripts. 


\title{
Olefin Purification and Selective Hydrogenation of
}

\section{Alkynes with Low Loaded Pd Nanoparticle}

\section{Catalysts}

Misael Cordoba ${ }^{1}$, Fernando Coloma-Pascual $^{2}$, Mónica E. Quiroga ${ }^{1,3}$, Cecilia R. Lederhos ${ }^{1 . *}$

${ }^{1}$ Instituto de Investigaciones en Catálisis y Petroquímica, INCAPE (FIQ-UNL, CONICET),

Colectora Ruta Nac. $N^{\circ} 168 \mathrm{Km}$ 0, Pje El Pozo, 3000 Santa Fe, Argentina.

${ }^{2}$ Servicios Técnicos de Investigación, Facultad de Ciencias, Universidad de Alicante, Apartado

99, E-03080 Alicante, Spain.

${ }^{3}$ Facultad de Ingeniería Química, Universidad Nacional del Litoral, Santiago del Estero 2829, 3000 Santa Fe, Argentina.

*E-mail: clederhos@fiq.unl.edu.ar

KEYWORDS: Selective Hydrogenation, Alkynes, Olefin Purification, Lindlar, Palladium Nanoparticles.

\begin{abstract}
The catalytic performance of Pd-nanoparticle catalysts for the selective hydrogenation of alkynes at mild conditions (150 $\mathrm{kPa}$ and $303 \mathrm{~K})$ was evaluated. A Lindlar commercial catalyst was also
\end{abstract}


tested for comparison. The effects of acidity, amount of active sites and dispersion on the catalytic activity and selectivity were studied. At mild conditions, Pd-nanoparticle catalysts were considerably more active and slightly more selective than the Lindlar catalyst. The best synthesized catalyst for the purification of 1-pentene was $\mathrm{Pd} / \mathrm{Al}_{2} \mathrm{O}_{3}-\mathrm{Mg}\left(\mathrm{r}^{0}=41.1 \mathrm{~mol} \mathrm{~g}_{\mathrm{Pd}^{-1}} \mathrm{~min}^{-1}\right.$, 94\% selectivity). The activity and selectivity of $\mathrm{Pd} / \mathrm{CaCO}_{3}$ were similar to those of the Lindlar catalyst. The smallest particle sizes $(3-4.5 \mathrm{~nm})$ favored the dissociative adsorption of hydrogen over $\mathrm{Pd}^{\circ}$ active sites and a good catalytic behavior. The weaker acid centers (Lewis) of $\mathrm{Pd} / \mathrm{Al}_{2} \mathrm{O}_{3}-\mathrm{Mg}$ and $\mathrm{Pd} / \mathrm{CaCO}_{3}$ favored higher selectivities to the desired alkene. $\mathrm{Pd} / \mathrm{Al}_{2} \mathrm{O}_{3}$ was the most active catalyst but also the least selective. This was due to strong acid sites, remnant Bronsted acid sites, which provide extra hydrogen that favors the alkyne hydrogenation rate and also the undesired overhydrogenation of the alkene and/or the isomerization.

\section{Introduction}

Olefins are very important products for the industries of fine chemicals, petrochemicals and polymers ${ }^{1,2}$. Industrial synthesis of alkenes can be carried out by several synthesis routes. In general lower molecular weight alkenes can be obtained in the petrochemical industry while higher alkenes can be synthesized through derivatives of this industry and by other methods ${ }^{3}$. Some of these processes include thermal treatment, dehydrogenation, catalytic cracking and hydrogenation $2,4,5$. After these processes not only desirable products are obtained, undesired products may also be present as alkanes, alkynes or other unsaturated products ${ }^{6,}$. Selective hydrogenation is a key process for the elimination of impurities or the obtaining of products with high added value. All selective hydrogenations are of great interest considering economic and ecological aspects ${ }^{2,8,9}$. Selective hydrogenation of alkynes to alkenes represents one of the most important steps in fine chemicals manufacture ${ }^{10}$. The highly selective hydrogenation of $\mathrm{C} \equiv \mathrm{C}$ 
triple bonds (alkynes) in presence of $\mathrm{C}=\mathrm{C}$ double bonds (alkenes) is of great relevance in order to obtain streams enriched in olefins for different processes ${ }^{11-14}$. The selective hydrogenation of small alkynes and alkadienes (acetylene, propyne, butyne) for the purification of olefin streams has been studied extensively ${ }^{15-17}$. Hydrogenation of bigger compounds is of great importance but has been studied less ${ }^{18-21}$.

Several authors have studied reactions of selective hydrogenation of medium to high molecular weight alkynes $\left(\mathrm{C}_{5}-\mathrm{C}_{7}{ }^{18,}\right.$, 19, 22-24, 3-methyl-1-pentyn-3-ol25, 2-methyl-3-butyn-2-ol ${ }^{20}$, ${ }^{26}$, phenyl acetylene ${ }^{27}$ and others ${ }^{28}$ ). Jackson et al. ${ }^{24}, 29-31$ studied the hydrogenation of alkynes/alkenes mixtures. They focused systematically on the selective hydrogenation of higher molecular weight alkynes, obtaining several important results about the reaction kinetics ${ }^{29-32}$. Murugesan et al. ${ }^{33}$ studied the elimination of phenylacetylene in the presence of styrene. Using Ni-fructose @ $\mathrm{SiO}_{2}-800,0.5 \mathrm{mmol}$ of phenylacetylene (5\%) were hydrogenated in the presence of $9.5 \mathrm{mmol}$ of styrene $(95 \%)$ at $353 \mathrm{~K}$ with $1 \mathrm{MPa} \mathrm{H}_{2}$ pressure. At these reaction conditions phenylacetylene was converted to $97 \%$ styrene and 3\% ethylbenzene.

Palladium is widely used in hydrogenation reactions due to its high hydrogenating capacity, being active and selective at low temperatures ${ }^{19,34,35}$. Overhydrogenation should however be avoided. Different factors can be manipulated to control Pd catalytic activity and selectivity: metal precursor salt, support, impregnation method, particle size and dispersion, and reaction conditions ${ }^{36,37}$. The classical Lindlar catalyst, consisting of $\mathrm{Pd}_{(5 \%)}$ supported on $\mathrm{CaCO}_{3}$ poisoned with a lead promoter (which greatly increases its selectivity), has been used since 1954 38,39 . Some disadvantages of this catalyst are: i) it has a high cost due to its high metal load, ii) it cannot be pelletized thus preventing easy separation and reuse, iii) restricted use, especially for the manufacture of food, cosmetic and medicine, because of the leaching of extremely toxic lead 
compounds. There is therefore a challenge for synthesizing new catalysts without these drawbacks and that can also improve the performance of Lindlar catalysts with comparable or higher selectivity to the desired product during hydrogenation processes of medium/large molecular weight alkynes. Several supported Pd catalysts have been prepared and evaluated for the selective hydrogenation of olefins, e.g. $\mathrm{Pd}_{(1 \%)} / \mathrm{Hydrotalcite}^{40}, \mathrm{Pd}_{4} \mathrm{~S} /$ carbon nanofiber ${ }^{6}$ and different bimetallic catalysts, $\mathrm{Pd}_{(0.4 \%)}-\mathrm{Ni}_{(0.5-1 \%)}{ }^{35,}{ }^{41}, \mathrm{Pd}_{(0.5 \%)}-\operatorname{In}_{(0.4 \%)}{ }^{42}, \mathrm{Pd}_{(1-5 \%)}-\mathrm{Bi}^{43}$. The kind of support can improve or decrease the activity/selectivity of the catalysts. Thus several supports have been tried to improve the catalytic properties of $\mathrm{Pd}$ : activated carbon ${ }^{19,}{ }^{44}, \mathrm{TiO}_{2}{ }^{37}, \mathrm{Fe}_{3} \mathrm{O}_{4}{ }^{45}$, mesoporous zeolites ${ }^{46}$, etc. In addition transition metal complexes can be considered as new active species or an intermediate of the active site ${ }^{46-48}$.

The objectives of this work are: i) to synthesize different Pd-nanoparticle catalysts using a $\mathrm{Pd}(\mathrm{II})$ ammine complex as a precursor salt and supports of different acidity strength $\left(\gamma-\mathrm{Al}_{2} \mathrm{O}_{3}, \gamma-\right.$ $\mathrm{Al}_{2} \mathrm{O}_{3}$ modified with $\mathrm{Mg}$ and $\mathrm{CaCO}_{3}$ ); ii) to evaluate the catalytic performances of the $\mathrm{Pd}$ nanoparticle catalysts for purifying 1-pentene (a medium chain olefin) and the selective hydrogenation of long/medium chain terminal alkyne $\left(\mathrm{C}_{7}\right.$ and $\left.\mathrm{C}_{5}\right)$ at mild reaction conditions; iii) to study the effects of the acidity (amount and strength), the type of active sites and the metal dispersion, on the catalytic activity and selectivity; iv) to compare the performance of the synthesized catalysts with that of a commercial Lindlar catalyst.

\section{Experimental Section}

\subsection{Catalyst Preparation}

Two inorganic materials, $\mathrm{CaCO}_{3}$ (Anedra, purity 98.6\%) and $\gamma-\mathrm{Al}_{2} \mathrm{O}_{3}(\mathrm{CK}-300$ powder, 3580 meshes, calcined $3 \mathrm{~h}$ at $823 \mathrm{~K}$ in air) were used as supports. $\mathrm{CaCO}_{3}$ was used without 
previous treatment. A fraction of alumina was impregnated with an aqueous solution of $\mathrm{MgSO}_{4} .7 \mathrm{H}_{2} \mathrm{O}$ (Anedra, purity $99.8 \%, 0.322 \mathrm{~g} \mathrm{MgSO}_{4} .7 \mathrm{H}_{2} \mathrm{O} / \mathrm{g}_{\text {alumina }}$ ) in order to obtain $5 \mathrm{wt} \%$ $\mathrm{Mg}$. Then it was dried $24 \mathrm{~h}$ at $373 \mathrm{~K}$ and calcined for $3 \mathrm{~h}$ at $823 \mathrm{~K}$, and was called $\mathrm{Al}_{2} \mathrm{O}_{3}-\mathrm{Mg}$.

The colorless complex of $\left[\mathrm{Pd}\left(\mathrm{NH}_{3}\right)_{4}\right] \mathrm{Cl}_{2}$ was prepared in a glass equipment under gentle stirring and reflux heating in a purified argon atmosphere. $0.5 \mathrm{~g}$ of $\mathrm{PdCl}_{2}$ (Aldrich, purity 99\%) and a solution of $55 \mathrm{~mL}$ of commercial $\mathrm{NH}_{3}$ (Cicarelli, purity 30\%) and $45 \mathrm{~mL}$ of $\mathrm{NH}_{3} / \mathrm{NH}_{4}^{+}$ buffer solution at $\mathrm{pH}=10.5$ were placed in the equipment and kept at $278 \mathrm{~K}$ for $4 \mathrm{~h}$.

$\mathrm{Pd} / \mathrm{Al}_{2} \mathrm{O}_{3}, \mathrm{Pd} / \mathrm{Al}_{2} \mathrm{O}_{3}-\mathrm{Mg}$ and $\mathrm{Pd} / \mathrm{CaCO}_{3}$ catalysts were obtained by incipient wetness impregnation. Three successive impregnations of the aqueous solution of $\left[\mathrm{Pd}\left(\mathrm{NH}_{3}\right)_{4}\right] \mathrm{Cl}_{2}$ were carried out on each support in order to obtain $0.4 \mathrm{wt} \% \mathrm{Pd}$ with intermediate drying at room temperature. Then the synthetized monometallic catalysts were dried at $393 \mathrm{~K}$ for $24 \mathrm{~h}$. The $\mathrm{Al}_{2} \mathrm{O}_{3}$ and $\mathrm{Al}_{2} \mathrm{O}_{3}-\mathrm{Mg}$ catalysts were calcined in air at $773 \mathrm{~K}$ for $3 \mathrm{~h}$ and the $\left[\mathrm{Pd}\left(\mathrm{NH}_{3}\right)_{4}\right] \mathrm{Cl}_{2} / \mathrm{CaCO}_{3}$ catalyst was calcined in a $\mathrm{N}_{2}$ stream at $673 \mathrm{~K}$ for $3 \mathrm{~h}$ in order to stabilize palladium nanoparticles and prevent the decomposition of $\mathrm{CaCO}_{3}$. Finally all catalysts were reduced $1 \mathrm{~h}$ with $\mathrm{H}_{2}\left(573 \mathrm{~K}, 50 \mathrm{~mL} \mathrm{~min}^{-1}\right)$ in a tubular continuous flow quartz reactor.

\subsection{Catalysts Characterization}

A Micromeritics ASAP 2020 instrument was used to obtain the nitrogen adsorptiondesorption isotherms at $0.02-0.98\left(\mathrm{P} / \mathrm{P}_{\mathrm{o}}\right)$ relative pressure. The BET model was used to calculate the specific surface area $\left(S_{\mathrm{BET}}\right)$ of the supports. Samples were first outgassed $2 \mathrm{~h}$ at $523 \mathrm{~K}$ in a vacuum and then $\mathrm{N}_{2}$ adsorption isotherms at $77 \mathrm{~K}$ were obtained. 
The mass content of Pd in the catalysts was determined by Atomic Emission Spectroscopy with Inductive Plasma (ICP-AES) with a Perkin Elmer OPTIMA 2120 equipment after digesting the samples in dilute sulfuric acid at $363 \mathrm{~K}$.

The acid strength and the amount of acid sites on the surface of the solids were measured by temperature programmed desorption using pyridine as a probe molecule (TPD-Py). Measurements were made in a tubular reactor coupled to a Shimadzu GC-8A gas chromatograph with a FID detector. Before the analysis $200 \mathrm{mg}$ of the samples were ex situ reduced at $573 \mathrm{~K}$ for $30 \mathrm{~min}$. The solids were then calcined in $\mathrm{N}_{2}\left(723 \mathrm{~K}, 40 \mathrm{~mL} \mathrm{~min}{ }^{-1}\right)$ to desorb physisorbed compounds. The samples were then cooled down to room temperature and a nitrogen stream saturated with pyridine was allowed to flow over the sample for 30 min. Weakly physisorbed pyridine was then removed by stripping with nitrogen $\left(418 \mathrm{~K}, 1 \mathrm{~h}, 40 \mathrm{~mL} \mathrm{~min}{ }^{-1}\right)$. Then the temperature was increased from 418 up to $1000 \mathrm{~K}$ at a heating rate of $10 \mathrm{~K} \mathrm{~min}^{-1}$. The gases issued by the reactor were directly sent to the methanator and analyzed with a flame ionization detector (FID). The signal of the detector was continuously recorded along with the sample temperature.

The electronic state of surface species was obtained by X-ray photoelectron spectroscopy (XPS). Ranges were chosen to inspect the $\mathrm{Pd} 3 \mathrm{~d}_{5 / 2}$ and $\mathrm{Ca} 2 \mathrm{p}_{3 / 2}$ signals as well as the $2 \mathrm{p}$ signals of $\mathrm{Mg}, \mathrm{Cl}$ and $\mathrm{Al}$. The measurements were made in a VG-Microtech Multilab instrument equipped with a $\mathrm{MgK}_{\alpha}$ source (hv: $1253.6 \mathrm{eV}$ ) and an energy of $50 \mathrm{eV}$. The pressure during data acquisition was maintained at $5.10^{-7} \mathrm{~Pa}$. The samples were previously reduced $1 \mathrm{~h}$ at $573 \mathrm{~K}$ in flowing hydrogen, following the same pretreatment conditions of the reaction tests. The areas of the peaks were estimated by calculating the integral of each peak after subtracting a Shirley background and fitting the experimental peak to a combination of Lorentzian/Gaussian lines of 
$30-70 \%$ proportions. The reference signals were the $\mathrm{Al} 2 \mathrm{p}$ at $74.7 \mathrm{eV}$ and the $\mathrm{Ca} 2 \mathrm{p}_{3 / 2}$ at 346.6 $\mathrm{eV}$, corresponding to the $\mathrm{Al}_{2} \mathrm{O}_{3}$ and $\mathrm{CaCO}_{3}$ supports.

The crystalline structure of the catalysts was defined in an X-ray Diffraction (XRD) Shimadzu XD-D1 equipment, with a $\operatorname{CuK}_{\alpha}(\lambda=1.5405 \AA)$ in the range $10<2 \theta<85^{\circ}$ at a scanning speed of $1^{\circ} \mathrm{min}^{-1}$. Samples powdered were reduced ex situ in $\mathrm{H}_{2}$ stream.

The metal particle size distribution was obtained by TEM using a JEOL 100 CX II electron microscope with an acceleration voltage of $100 \mathrm{kV}$ and 270000x magnification. The samples were prepared by grinding the pellets, suspending the particles in ethanol and then sonicating for 15 min. A drop of this suspension was placed on a 200 mesh copper grid with a Formvar film and observed. A set of digital images were taken in order to identify the phases and measure the particle diameters. Digital Micrograph software was used to obtain the particle size distributions.

The reducibility of the surface species was evaluated by temperature programmed reduction ( $\mathrm{H}_{2}$-TPR). The measurements were made in a Micromeritics Auto Chem II equipment equipped with a thermal conductivity detector. Before the analysis the samples were subjected to a pretreatment in $\mathrm{Ar}$ at $673 \mathrm{~K}$ for $30 \mathrm{~min}$, and then they were cooled down to room temperature. The reduction procedure was carried out using a mixture of $5 \% \mathrm{H}_{2}$ in $\mathrm{Ar}$ at a flowrate of $30 \mathrm{~mL}$ $\mathrm{min}^{-1}$ and heating ramp of $10 \mathrm{~K} \mathrm{~min}^{-1}$ from room temperature to $1273 \mathrm{~K}$.

\subsection{Catalytic Tests}

The catalysts were evaluated with the selective hydrogenation of 1-heptyne (Fluka, Cat. No. 51950, >98\%), 1-pentyne (Aldrich, Cat. No. 627-19-0, >99\%) and a mixture of 30/70 \% v/v $1-$ pentyne:1-pentene (Aldrich, Cat. No. 109-67-1,>98.5\%) at mild conditions, $150 \mathrm{kPa}$ and $303 \mathrm{~K}$. In each run $50 \mathrm{~mL}$ of $2 \% \mathrm{v} / \mathrm{v}$ reactant diluted in toluene (Merck, Cat. No. TX0735-44, >99\%) 
were put in a stainless steel batch reactor coated with polytetrafluoroethylene (PTFE), with a reactant/Pd molar ratio of 1100 . Stirring at $750 \mathrm{rpm}$ was used in order to eliminate external diffusional limitations ${ }^{49}$. Reagents and products were analyzed by gas chromatography (GC) with a FID detector and an HP INNOWax capillary column of polyethyleneglycol (PEG). The Lindlar commercial catalyst (Aldrich, Cat. No. 20,573-7) was used for comparative purposes without any pretreatment as suggested by other authors for the hydrogenation of alkynes ${ }^{50}$.

\section{Results and Discussion}

\subsection{Catalysts Characterization}

The nitrogen sortometry results are shown in Table 1 . Surface area $\left(\mathrm{S}_{\mathrm{BET}}\right), \mathrm{V}_{\mathrm{p}}$ (average pore volume) and $d_{p}$ (average pore diameter) were calculated from $\mathrm{N}_{2}$ physisorption isotherms for the three supports used: $\mathrm{Al}_{2} \mathrm{O}_{3}, \mathrm{Al}_{2} \mathrm{O}_{3}-\mathrm{Mg}$ and $\mathrm{CaCO}_{3}$. All supports had different surface areas. $\mathrm{Al}_{2} \mathrm{O}_{3}$ displayed the largest $\mathrm{BET}$ area, while $\mathrm{CaCO}_{3}$ had the lowest. The $\mathrm{Al}_{2} \mathrm{O}_{3}$ support modified with $\mathrm{Mg}\left(\mathrm{Al}_{2} \mathrm{O}_{3}-\mathrm{Mg}\right)$ had a remarkable reduction of the surface area, attributed to the incorporation of magnesium on the surface of $\mathrm{Al}_{2} \mathrm{O}_{3}$. The textural properties varied in the same way, $\mathrm{Al}_{2} \mathrm{O}_{3}$ pore volume being much higher than the pore volume of $\mathrm{Mg}$ doped alumina. These results are important because they can give an idea of the exposed surface area of the supports and their interaction with the precursor metal complex. On the other hand, the average pore diameter, $\mathrm{d}_{\mathrm{p}}$, of $\mathrm{CaCO}_{3}$ was $10 \%$ higher than the $\mathrm{d}_{\mathrm{p}}$ of $\mathrm{Al}_{2} \mathrm{O}_{3}$. The $\mathrm{d}_{\mathrm{p}}$ of $\mathrm{Al}_{2} \mathrm{O}_{3}-\mathrm{Mg}$ was $25 \%$ lower than the $\mathrm{d}_{\mathrm{p}}$ of $\mathrm{Al}_{2} \mathrm{O}_{3}$. The relative pore diameter loss of $\mathrm{Al}_{2} \mathrm{O}_{3}-\mathrm{Mg}$ must be due to the preferential deposition of magnesium particles in pore mouths. 
Table 1. Results of $\mathrm{N}_{2}$ physisorption isotherms of supports

\begin{tabular}{cccc}
\hline Support & $\begin{array}{c}\mathbf{S}_{\text {BET }} \\
\left(\mathbf{m}^{\mathbf{2}} \mathbf{g}^{-1}\right)\end{array}$ & $\begin{array}{c}\mathbf{V}_{\mathbf{p}} \\
\left(\mathbf{c m}^{\mathbf{3}} \mathbf{g}^{-1}\right)\end{array}$ & $\begin{array}{c}\mathrm{d}_{\mathrm{p}} \\
\mathbf{( n m})\end{array}$ \\
\hline $\mathbf{A l}_{\mathbf{2}} \mathbf{O}_{\mathbf{3}}$ & 180 & 0.53 & 9.6 \\
$\mathbf{A l}_{\mathbf{2}} \mathbf{O}_{\mathbf{3}}-\mathbf{M g}$ & 120 & 0.22 & 7.2 \\
$\mathbf{C a C O}_{3}$ & 4 & 0.01 & 10.6 \\
\hline
\end{tabular}

Results of temperature programmed desorption of pyridine of the supports (a) and the catalysts (b) are shown in Figure 1. The TPD traces had three desorption regions with different intensity. Region-I, located at low temperatures (400-600 K), Region-II at medium temperatures $(600-760 \mathrm{~K})$ and Region-III at high temperatures $(760-1000 \mathrm{~K})$. These regions correspond to sites of weak, moderate or strong acidity, respectively ${ }^{51-53}$. According to different authors ${ }^{54,55}$, the peaks of weak acidity can be attributed to Lewis acid sites, the peaks of moderate acidity to a combination of Lewis and Brönsted acid sites, while strong acid sites would be Brönsted sites. According to Figure 1.a the three supports had different types of acid sites. $\mathrm{Al}_{2} \mathrm{O}_{3}$ and $\mathrm{Al}_{2} \mathrm{O}_{3}-\mathrm{Mg}$ supports had two peaks of different intensities at high and low temperatures indicating the presence of both Lewis and Brönsted sites. In the case of $\mathrm{CaCO}_{3}$, a single peak is seen at low temperature, indicating the sole presence of weak Lewis sites. 

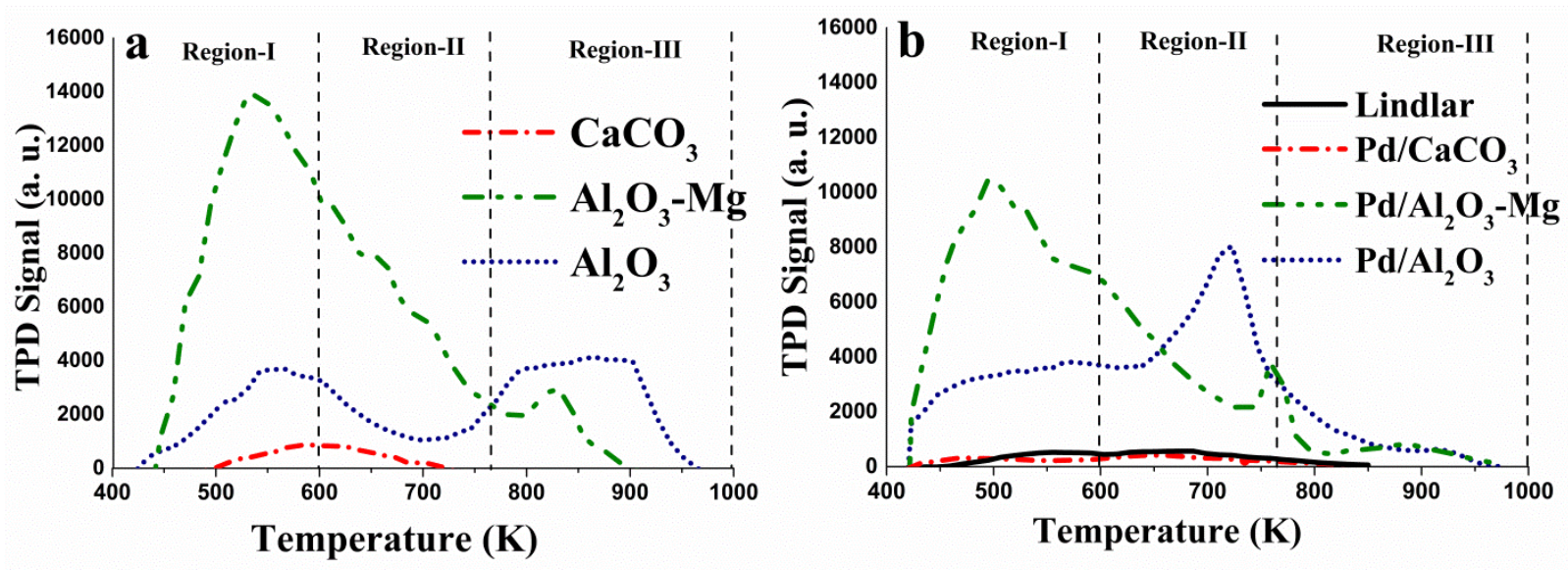

Figure 1. TPD-Py results. a) Supports. b) Catalysts.

Figure 1.b shows the TPD-Py traces of the Pd catalysts. It can be seen that the $\mathrm{Pd} / \mathrm{Al}_{2} \mathrm{O}_{3}$ trace is very different from that of the Pd-free support, the area of Region-I increased markedly, a pronounced peak in the Region-II ca. $723 \mathrm{~K}$ appeared and the strong acidity peak of Region-III almost disappeared. Besides, the $\mathrm{Pd} / \mathrm{Al}_{2} \mathrm{O}_{3}-\mathrm{Mg}$ TPD-Py trace was shifted to lower temperatures. $\mathrm{Pd} / \mathrm{CaCO}_{3}$ and Lindlar traces are quite similar to that of the Pd-free support.

The pyridine TPD traces were integrated to give the total amount of weak (400- $600 \mathrm{~K})$, mild (600-760 K) and strong acid sites $(\mathrm{T}>760 \mathrm{~K})$. These acidity values were included in Table 2. Regarding the acidity values of the $\gamma-\mathrm{Al}_{2} \mathrm{O}_{3}$ fresh support, this had three kinds of acid sites, mainly strong (Brönsted). $\mathrm{Al}_{2} \mathrm{O}_{3}-\mathrm{Mg}$ support had the highest acidity, mainly attributed to the increase of the weak and medium acidity of $\mathrm{Al}_{2} \mathrm{O}_{3}$ (Lewis), while the strong acidity (Brönsted) was drastically reduced. This can be explained in Scheme 1 by the addition of $\mathrm{Mg}$ sulfate that produced two effects: (i) the transfer of a proton of the surface hydroxide groups (Brönsted acid sites) to the aqueous anion sulfate (Brönsted basic site); (ii) the bonding of aqueous $\mathrm{Mg}^{2+}($ Lewis acid site) to the remnant surface oxidic site (Lewis basic site). 


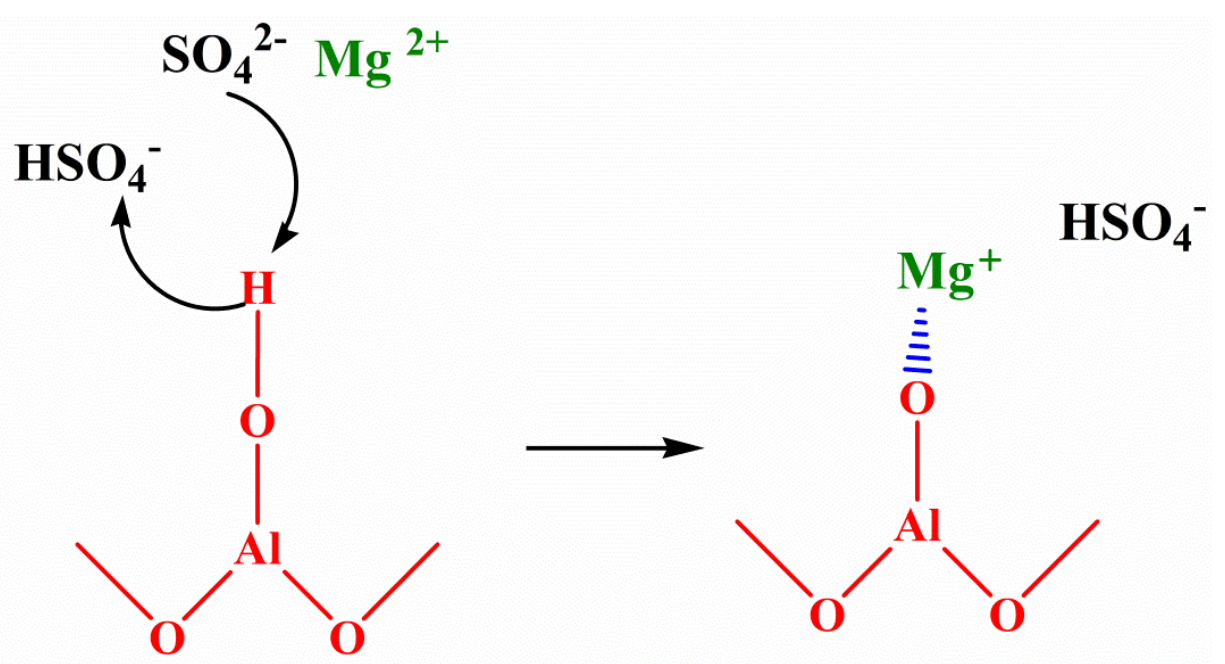

Scheme 1. Schematic drawing of simultaneous proton and ion-exchange on alumina Brönsted sites during $\mathrm{MgSO}_{4}$ impregnation

The $\mathrm{CaCO}_{3}$ support exhibited the lowest total acidity, only related to $\mathrm{Ca}^{2+}$ Lewis acid sites. This is related to the basic characteristics of this support, $\mathrm{CO}_{3}{ }^{2-}$ being a soft basic Lewis site.

A marked increase in total acidity upon Pd addition is observed in Table 2. The observed order of total and weak acidity strength was: $\mathrm{Pd} / \mathrm{Al}_{2} \mathrm{O}_{3}-\mathrm{Mg}>>\mathrm{Pd} / \mathrm{Al}_{2} \mathrm{O}_{3}>>$ Lindlar $>$ $\mathrm{Pd} / \mathrm{CaCO}_{3}$. The order of medium acidity strength was $\mathrm{Pd} / \mathrm{Al}_{2} \mathrm{O}_{3}>\mathrm{Pd} / \mathrm{Al}_{2} \mathrm{O}_{3}-\mathrm{Mg}>>$ Lindlar $>$ $\mathrm{Pd} / \mathrm{CaCO}_{3}$. Total, medium and weak acidity of Lindlar and $\mathrm{Pd} / \mathrm{CaCO}_{3}$ were the lowest. This was mainly due to the basic character of the support. The TPD-Py profile of the $\mathrm{Pd} / \mathrm{Al}_{2} \mathrm{O}_{3}-\mathrm{Mg}$ catalyst showed that the incorporation of $\mathrm{Mg}(\mathrm{II})$ and $\mathrm{Pd}(\mathrm{II})$ species over the alumina support, has the greatest effect on the quantity and quality of acidic properties, exhibiting greater weak acidity and higher total acidity, but a decrease of medium acidity in comparison to the $\mathrm{Pd} / \mathrm{Al}_{2} \mathrm{O}_{3}$ catalyst. Feng et $\mathrm{al}^{56,57}$ showed a similar behavior in their studies using the TPD-NH $\mathrm{N}_{3}$ technique for a series of $\mathrm{Pd}-\mathrm{Mg}$ based catalysts ( $\mathrm{Pd} / \mathrm{MgAl}-\mathrm{LDH} / \mathrm{Al}_{2} \mathrm{O}_{3}, \mathrm{PdO} / \mathrm{MgO}-\mathrm{Al}_{2} \mathrm{O}_{3}, \mathrm{MgO}$ modified $\mathrm{Pd} / \mathrm{Al}_{2} \mathrm{O}_{3}$ and $\mathrm{Im}-\mathrm{PdO} / \mathrm{MgO}-\mathrm{Al}_{2} \mathrm{O}_{3}$ ). The acidity increase was attributed to the presence of $\mathrm{Pd}$ 
species, responsible for different types of Lewis acid sites and the loss of Brönsted sites of the catalysts. As shown in Scheme 2, during the synthesis of the catalysts, at $\mathrm{pH} \cong 10.5$, the Brönsted acid groups of the alumina or alumina modified supports would transfer the proton of the surface OH groups (Brönsted acid site) to the ammonia solvent (Brönsted basic site) and simultaneously the remnant oxidic site (Lewis basic Site) would bonds to Pd(II), a Lewis acid site, of the $\left[\mathrm{Pd}\left(\mathrm{NH}_{3}\right)_{4}\right]^{2+}$ complex. Previously, Brunelle ${ }^{58}$ stated that at $\mathrm{pH}$ values below its IP (isoelectric point) an oxide particle adsorbs compensating anions like $\left[\mathrm{PdCl}_{4}\right]^{2-}$, while at $\mathrm{pH}$ values above its IP, the surface acquires a net negative charge and adsorbs cations, like $\left[\mathrm{Pd}\left(\mathrm{NH}_{3}\right)_{4}\right]^{2+}$.

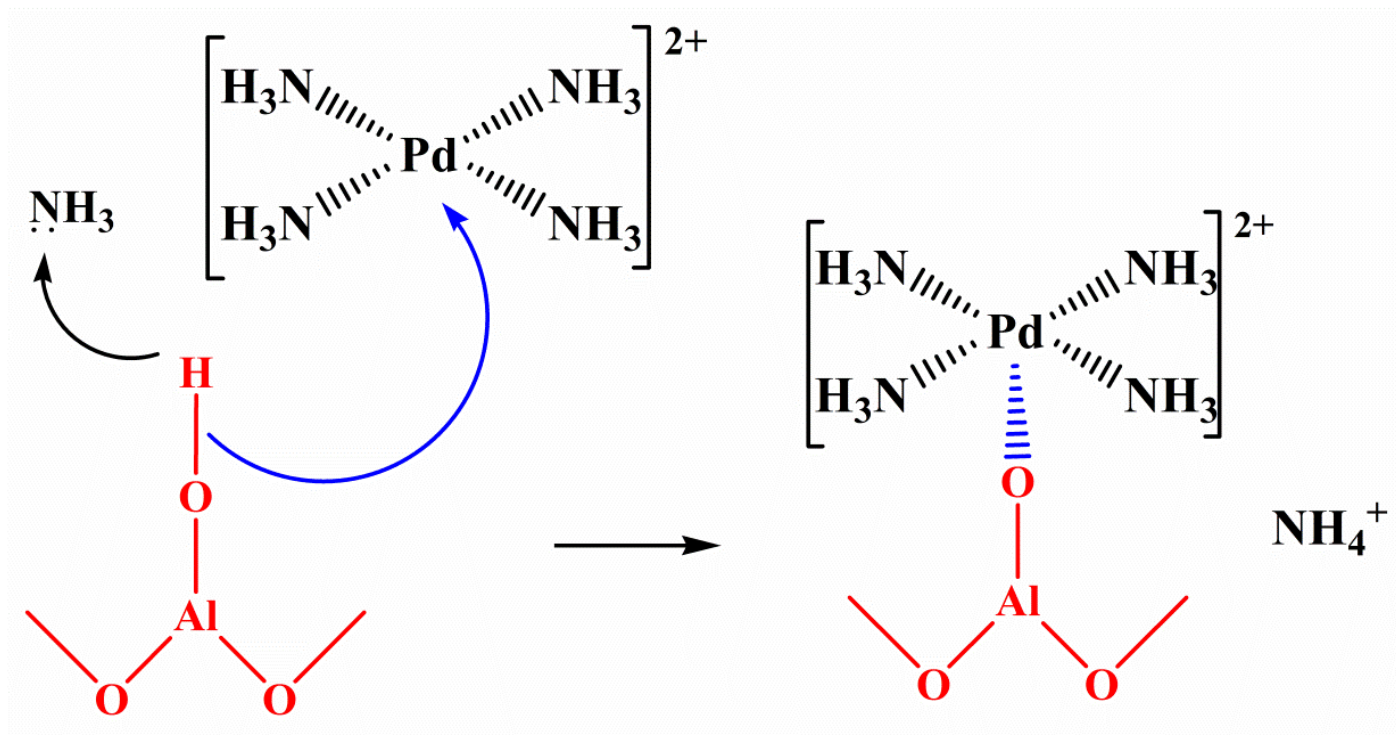

Scheme 2. Schematic drawing of simultaneous proton and ion-exchange on alumina free or modified during the impregnation of $\left[\mathrm{Pd}\left(\mathrm{NH}_{3}\right)_{4}\right]^{2+}$ in ammonia media. 
Table 2. TPD-Py results.

\begin{tabular}{ccccc}
\hline Sample & $\begin{array}{c}\text { Total Acidity } \\
\left(\mu \mathbf{m o l}_{\mathbf{P y}} \mathbf{g}^{-1}\right)\end{array}$ & $\begin{array}{c}\text { Weak Acidity } \\
\left(\mu \mathbf{m o l}_{\mathbf{P y}} \mathbf{g}^{-1}\right)\end{array}$ & $\begin{array}{c}\text { Medium Acidity } \\
\left(\mu \mathbf{m o l}_{\mathbf{P y}} \mathbf{g}^{-1}\right)\end{array}$ & $\begin{array}{c}\text { Strong Acidity } \\
\left(\mu \mathbf{m o l}_{\mathbf{P y}} \mathbf{g}^{-1}\right)\end{array}$ \\
\hline $\mathbf{A l}_{\mathbf{2}} \mathbf{O}_{\mathbf{3}}$ & 32.61 & 7.09 & 7.38 & 18.15 \\
$\mathbf{A l}_{\mathbf{2}} \mathbf{O}_{\mathbf{3}}-\mathbf{M g}$ & 63.58 & 24.73 & 35.00 & 3.85 \\
$\mathbf{C a C O}_{\mathbf{3}}$ & 1.00 & 1.00 & -- & --- \\
\hline $\mathbf{P d} / \mathbf{A l}_{\mathbf{2}} \mathbf{O}_{3}$ & 56.76 & 18.72 & 37.82 & 0.22 \\
$\mathbf{P d} / \mathbf{A l}_{\mathbf{2}} \mathbf{O}_{\mathbf{3}}-\mathbf{M g}$ & 72.92 & 53.31 & 19.32 & 0.29 \\
$\mathbf{P d} / \mathbf{C a C O}_{3}$ & 4.27 & 0.88 & 3.39 & --- \\
$\mathbf{L i n d l a r}$ & 5.26 & 1.17 & 4.09 & -- \\
\hline
\end{tabular}

Results of characterization of the metal function by chemical analysis (ICP), XPS and TEM are shown in Table 3 for the $\mathrm{Pd} / \mathrm{Al}_{2} \mathrm{O}_{3}-\mathrm{Mg}, \mathrm{Pd} / \mathrm{CaCO}_{3}$ and Lindlar catalysts. The Lindlar catalyst had a very high $\mathrm{Pd}$ content, similar to that of commercial catalysts. In the case of the $\mathrm{Pd} / \mathrm{Al}_{2} \mathrm{O}_{3}$ sample, the ICP analysis gave a Pd mass content very similar to the theoretical value. Slightly lower contents were found for the $\mathrm{Pd} / \mathrm{Al}_{2} \mathrm{O}_{3}-\mathrm{Mg}$ and $\mathrm{Pd} / \mathrm{CaCO}_{3}$ catalysts. The presence of $\mathrm{Mg}$ was also confirmed by ICP analysis, as $5.5 \mathrm{wt} \%$ of $\mathrm{Mg}$ was detected during the preparation of the support. 
Table 3. Metal loading as determined by ICP. Average particle size $\left(d_{T E M}\right)$ and dispersion $(D)$ from TEM microscopy. XPS results.

\begin{tabular}{|c|c|c|c|c|c|c|c|c|}
\hline \multirow{3}{*}{ Sample } & \multirow{3}{*}{$\begin{array}{c}\text { Pd } \\
(\text { wt \%) }\end{array}$} & \multirow{3}{*}{$\begin{array}{l}d_{T E M} \\
(\mathrm{~nm})\end{array}$} & \multirow{3}{*}{$\begin{array}{c}\text { D } \\
(\%)\end{array}$} & \multicolumn{5}{|c|}{ XPS } \\
\hline & & & & & $\begin{array}{l}\text { Pd 3d } \\
\text { BE (e) }\end{array}$ & & \multirow{2}{*}{$\begin{array}{l}\mathrm{Pd} / \mathrm{S}^{*} \\
\left(\% \%^{\mathrm{at}} / \mathrm{at}\right)\end{array}$} & \multirow{2}{*}{$\begin{array}{l}\mathrm{Cl} / \mathrm{Pd} \\
\left(\% \%^{\mathrm{at}} / \mathrm{at}\right.\end{array}$} \\
\hline & & & & $\mathbf{P d}^{\mathbf{0}}$ & $\mathbf{P d}^{\delta+}$ & $\mathbf{P d}^{\mathbf{n}^{+}}$ & & \\
\hline $\mathbf{P d} / \mathrm{Al}_{2} \mathrm{O}_{3}$ & 0.38 & 2.9 & 39 & $\begin{array}{c}334.7 \\
(62 \%)\end{array}$ & & $\begin{array}{c}336.3 \\
(38 \%)\end{array}$ & 0.0016 & 2.09 \\
\hline $\mathrm{Pd} / \mathrm{Al}_{2} \mathrm{O}_{3}-\mathrm{Mg}$ & 0.30 & 3.0 & 37 & $\begin{array}{c}334.9 \\
(100 \%)\end{array}$ & & -- & 0.0063 & 0.95 \\
\hline $\mathrm{Pd} / \mathrm{CaCO}_{3}$ & 0.22 & 4.4 & 25 & $\begin{array}{c}335.0 \\
(100 \%)\end{array}$ & -- & -- & 0.022 & 5.14 \\
\hline Lindlar & 5.00 & 46.0 & $2.5^{35}$ & -- & $\begin{array}{c}335.2 \\
(69 \%)\end{array}$ & $\begin{array}{c}336.9 \\
(31 \%)\end{array}$ & 0.243 & -- \\
\hline
\end{tabular}

* $\mathrm{Pd} / \mathrm{S}$ : atomic ratio $\mathrm{Pd} / \mathrm{Al}$ for $\mathrm{Pd} / \mathrm{Al}_{2} \mathrm{O}_{3}$ or $\mathrm{Pd} / \mathrm{Al}_{2} \mathrm{O}_{3}-\mathrm{Mg}$. $\mathrm{Pd} / \mathrm{Ca}$ for $\mathrm{Pd} / \mathrm{CaCO}_{3}$ and Lindlar.

Figure 2 shows the TEM images and particle size distribution of the catalysts. Table 3 gives the average particle size $\left(d_{T E M}\right)$ as determined by TEM and according to Equation (I):

$$
d_{T E M}=\frac{\sum n_{i} \cdot d_{i}^{3}}{\sum n_{i} \cdot d_{i}^{2}}
$$

Where $n_{i}$ is the number of particles with particle size $d_{i}$. 


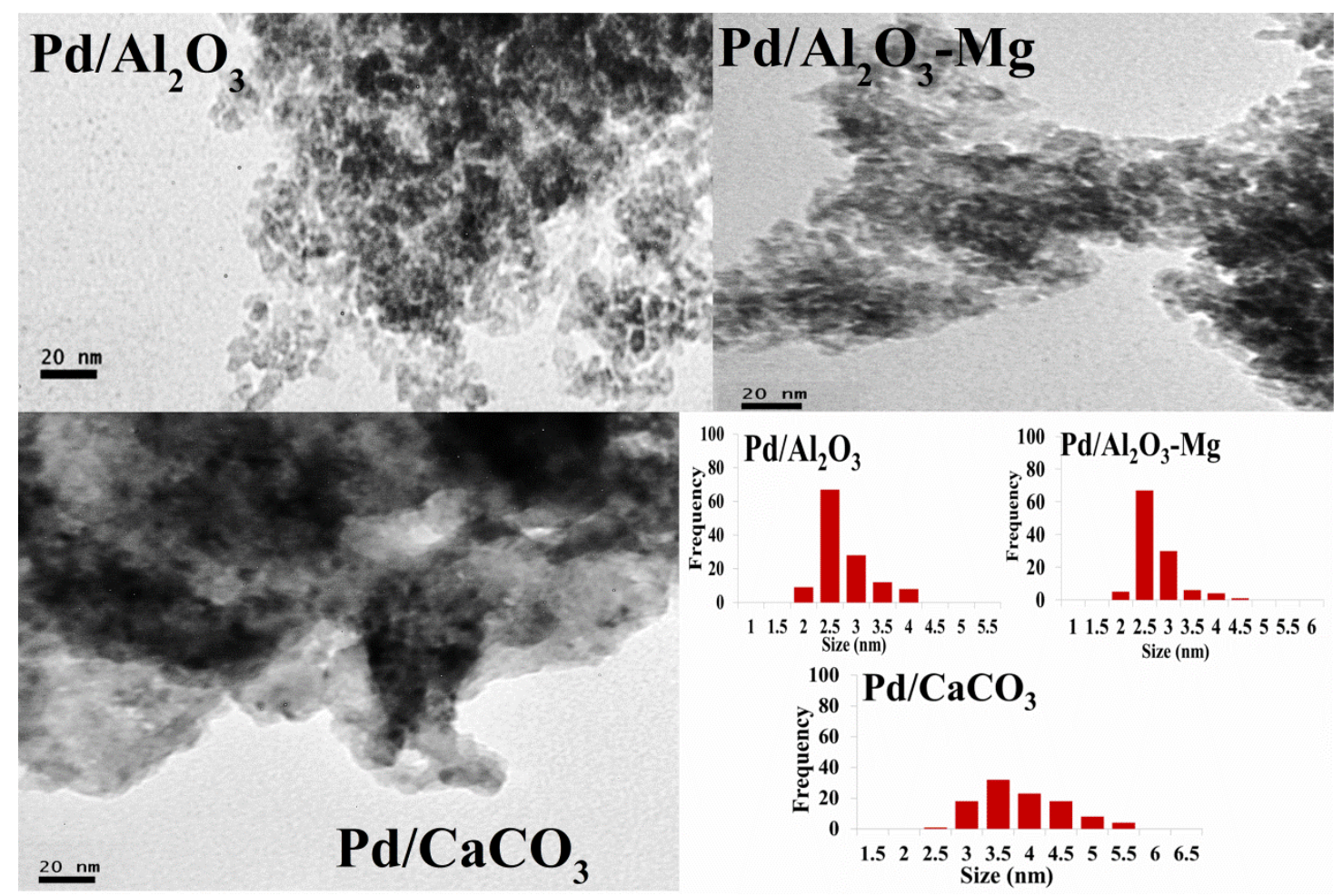

Figure 2. TEM images and particle size distribution of the catalysts.

The average particle sizes were very similar for $\mathrm{Pd} / \mathrm{Al}_{2} \mathrm{O}_{3}-\mathrm{Mg}$ and $\mathrm{Pd} / \mathrm{Al}_{2} \mathrm{O}_{3}, 3.0$ and $2.9 \mathrm{~nm}$, respectively. This indicates that the incorporation of magnesium in the support does not significantly affect the particle size, mainly because of the low palladium loading. For the $\mathrm{Pd} / \mathrm{CaCO}_{3}$ catalyst the particle size is slightly higher: $4.4 \mathrm{~nm}$. From these results, considering the spherical particle model adopted by Paryjczak and Szymura ${ }^{59}$ and using $\rho_{\mathrm{Pd}}=1.20210^{7} \mathrm{~g}_{\mathrm{Pd}} \mathrm{m}^{-3}$; $\sigma_{\mathrm{Pd}}=1.2710^{19} \mathrm{at}_{\mathrm{Pd}} \mathrm{m}^{-2}$, the metal dispersions $\mathrm{D}$ were calculated and presented in Table 3 . In $\mathrm{Pd} / \mathrm{Al}_{2} \mathrm{O}_{3}-\mathrm{Mg}$ and $\mathrm{Pd} / \mathrm{Al}_{2} \mathrm{O}_{3}$ a very similar dispersion of metal active sites is observed on both supports $(\sim 39 \%)$, while for the $\mathrm{Pd} / \mathrm{CaCO}_{3}$ catalyst a lower dispersion of $25 \%$ is obtained. These results may be indicative of greater interaction of the precursor complex with the $\mathrm{Al}_{2} \mathrm{O}_{3}$ and $\mathrm{Al}_{2} \mathrm{O}_{3}-\mathrm{Mg}$ supports during wet impregnation due to its more acidic characteristics (Table 2) and similar specific surface area, as explained previously. It is also possible that the small pore 
volume of the $\mathrm{CaCO}_{3}$ support (see Table 1) favors a lower final dispersion because of palladium preferential deposition in pore mouths, thus blocking the pore structure.

The commercial Lindlar catalyst has a quite high average particle size $(46 \mathrm{~nm})$ and a lower dispersion (2.5\%) than the prepared catalysts (Table 3). This can be attributed to a high amount of Pd having been deposited on a support of low area and acidity, thus promoting a greater agglomeration of the particles in the pore mouths.

Figure 3 shows the TPR traces of the prepared catalysts. The reduction of species at temperatures below $250 \mathrm{~K}$ cannot be observed due to equipment limitations. The $\mathrm{Pd} / \mathrm{CaCO}_{3}$, $\mathrm{Pd} / \mathrm{Al}_{2} \mathrm{O}_{3}$ and $\mathrm{Pd} / \mathrm{Al}_{2} \mathrm{O}_{3}-\mathrm{Mg}$ catalysts exhibited an initial reduction peak at 260, 285 and $299 \mathrm{~K}$, respectively. This peak at low temperatures is assigned to the reduction of bulk PdO species to metallic palladium ${ }^{60}$; indicating that palladium is at least partly in the $\operatorname{Pd}^{\circ}$ metal state after the reduction treatment before the catalytic tests. For these peaks, a shift to higher temperatures is observed in this order: $\mathrm{Pd} / \mathrm{CaCO}_{3}<\mathrm{Pd} / \mathrm{Al}_{2} \mathrm{O}_{3}<\mathrm{Pd} / \mathrm{Al}_{2} \mathrm{O}_{3}-\mathrm{Mg}$ which could indicate higher interaction forces between the metallic species with the support, consistent with the amount of weak acidity (related to Lewis sites). Figure 3 also shows that during TPR analysis, $\mathrm{Pd} / \mathrm{CaCO}_{3}$, $\mathrm{Pd} / \mathrm{Al}_{2} \mathrm{O}_{3}$ and $\mathrm{Pd} / \mathrm{Al}_{2} \mathrm{O}_{3}-\mathrm{Mg}$ had a negative peak at 266, 325 and $340 \mathrm{~K}$, respectively ${ }^{60}$, due to the release of hydrogen from the decomposition of the $\beta$-phase of Pd hydrides ( $\beta$-HPd) formed during the reduction of $\mathrm{PdO}$ at low temperatures ${ }^{60}$. These species interact weakly with the support and therefore Pd can be easily reduced. 

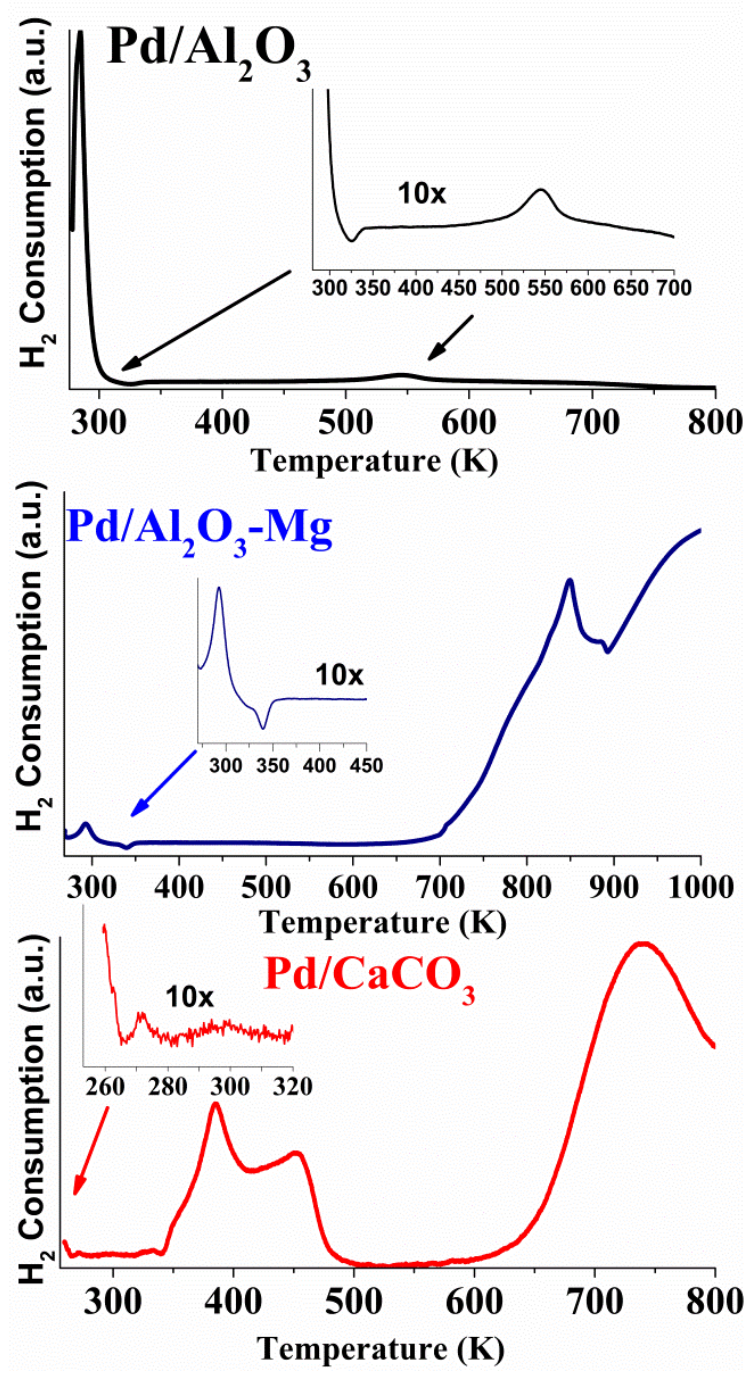

Figure 3. $\mathrm{H}_{2}$-TPR traces of $\mathrm{Pd} / \mathrm{Al}_{2} \mathrm{O}_{3}, \mathrm{Pd} / \mathrm{Al}_{2} \mathrm{O}_{3}-\mathrm{Mg}$ and $\mathrm{Pd} / \mathrm{CaCO}_{3}$.

In Figure 3, medium intensity peaks at 385 and $451 \mathrm{~K}$, and a very weak peak around $543 \mathrm{~K}$ are also observed on $\mathrm{Pd} / \mathrm{CaCO}_{3}$ and $\mathrm{Pd} / \mathrm{Al}_{2} \mathrm{O}_{3}$ samples, respectively. Some authors suggest that the hydrogen consumption at these temperatures is due to the reduction of $\mathrm{Pd}_{\mathrm{x}} \mathrm{O}_{\mathrm{y}} \mathrm{Cl}_{\mathrm{z}}$ oxychlorinated species or the reduction of $\mathrm{Pd}^{2+}$ ions stabilized by adjacent $\mathrm{Cl}^{-}$remaining after the calcination process ${ }^{61}$. For $\mathrm{Pd} / \mathrm{Al}_{2} \mathrm{O}_{3}-\mathrm{Mg}$ two extremely large peaks are observed in Figure 3 at temperatures higher than $700 \mathrm{~K}$. They are both attributed to the reduction of the remaining sulfate magnesium precursor $\left(\mathrm{SO}_{4}{ }^{2-}\right)$ that generates residual $\mathrm{H}_{2} \mathrm{~S}$ or $\mathrm{SO}_{3}{ }^{62}$. Additionally, in the 
$\mathrm{Pd} / \mathrm{CaCO}_{3}$ sample, a wide peak between 633 and $800 \mathrm{~K}$ is seen that can be attributed to the decomposition of $\mathrm{CaCO}_{3}{ }^{63,64}$.

Figure 4 shows the XPS spectra of the $\mathrm{Pd} 3 d$ region of $\mathrm{Pd} / \mathrm{Al}_{2} \mathrm{O}_{3}, \mathrm{Pd} / \mathrm{Al}_{2} \mathrm{O}_{3}-\mathrm{Mg}$ and $\mathrm{Pd} / \mathrm{CaCO}_{3}$ pretreated in hydrogen at $573 \mathrm{~K}$, showing the $\mathrm{Pd} 3 d_{5 / 2}$ and $3 d_{3 / 2}$ signals separated by approximately $5 \mathrm{eV}$, in accordance with literature values ${ }^{65}$. The points are the experimental data and the curves beneath are the corresponding deconvoluted peaks. Figure 4 also shows the XPS spectrum of the $\mathrm{Mg} 2 p$ region of $\mathrm{Pd} / \mathrm{Al}_{2} \mathrm{O}_{3}-\mathrm{Mg}$. The $\mathrm{Pd} 3 d$ and $\mathrm{Pb} 4 f$ signals of the classical Lindlar catalyst ${ }^{34}$ are also presented for comparative purposes. The deconvolution of the $\mathrm{Pd} 3 d_{5 / 2}$ spectrum resulted in two peaks for the $\mathrm{Pd} / \mathrm{Al}_{2} \mathrm{O}_{3}$ and Lindlar samples, indicating the presence of two different species of $\mathrm{Pd}$ on the catalysts. $\mathrm{Pd} / \mathrm{Al}_{2} \mathrm{O}_{3}-\mathrm{Mg}$ and $\mathrm{Pd} / \mathrm{CaCO}_{3}$ spectra had one peak in the $\mathrm{Pd} 3 d_{5 / 2}$ region, confirming the presence of single Pd species. These results are detailed in Table 3. The $\mathrm{Pd} / \mathrm{Al}_{2} \mathrm{O}_{3}$ catalyst presents two $\mathrm{BE}$ peaks for $\mathrm{Pd} 3 d_{5 / 2}$ at $334.7(62 \%$ at $/$ at $)$ and 336.3 $\mathrm{eV}\left(38 \%\right.$ at/at), which are assigned to $\mathrm{Pd}^{\circ}$ and $\mathrm{Pd}^{n+}$ (with $n$ close to 2) electrodeficient oxychlorinated species formed during the calcination pretreatment ${ }^{61}$. The deconvolution of the $\operatorname{Pd} 3 d_{5 / 2}$ signal for the Lindlar catalyst indicates two peaks at $335.2 \mathrm{eV}(69 \%$ at $/$ at $)$ and $336.9 \mathrm{eV}$ (31\% at/at), assigned to $\mathrm{Pd}^{\delta+}$ (with $\delta$ close to 0 ) and electrodeficient $\mathrm{Pd}^{n+}$ species (with $n$ close to $2)^{34,66}$. The deconvolution of the $\mathrm{Pb} 4 f_{7 / 2}$ spectrum for the Lindlar catalyst shows two peaks at $136.8 \mathrm{eV}(20 \%$ at $/$ at $)$ and $138.6(80 \%$ at $/$ at $)$, attributed to $\mathrm{Pb}^{\circ}$ and $\mathrm{Pb}(\mathrm{OAc})_{2}$, respectively ${ }^{34,66}$. In the case of the $\mathrm{Pd} / \mathrm{Al}_{2} \mathrm{O}_{3}-\mathrm{Mg}$ and $\mathrm{Pd} / \mathrm{CaCO}_{3}$ catalysts the palladium signal is observed at a $\mathrm{BE}$ of 334.9 and $335.0 \mathrm{eV}(100 \%$ at/at $)$, respectively, indicating the presence of the totally reduced $\mathrm{Pd}^{\circ}$ at surface level, according to the literature ${ }^{66}$. In the $\mathrm{Pd} / \mathrm{Al}_{2} \mathrm{O}_{3}-\mathrm{Mg}$ catalyst the $\mathrm{BE}$ of the $\mathrm{Mg} 2 p$ signal was located at $51.6 \mathrm{eV}$ and was attributed to $\mathrm{MgO}$ surface species ${ }^{66}$ seemingly confirmed by the ICP analysis. Deconvolution of the XPS spectra of the Pd prepared catalysts also showed 
a peak at ca. $198.5 \mathrm{eV}$ that corresponds to $\mathrm{Cl} 2 p_{3 / 2}$. This was associated to surface chloride species ${ }^{66}$ not complete eliminated after reduction.
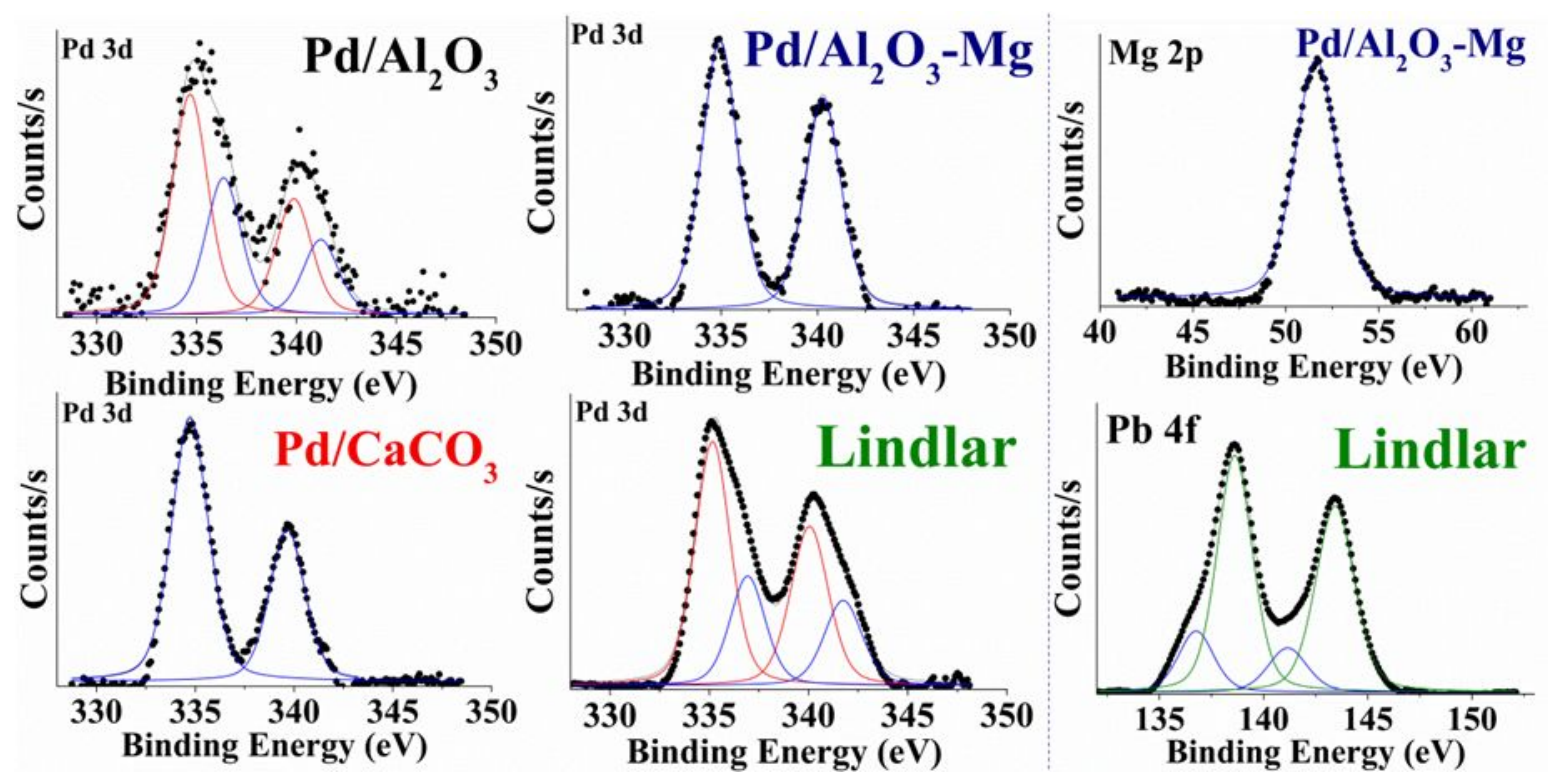

Figure 4. XPS spectra of the $\mathrm{Pd} 3 d$ region of all catalysts. $\mathrm{Mg} 2 p$ of $\mathrm{Pd} / \mathrm{Al}_{2} \mathrm{O}_{3}-\mathrm{Mg}$. $\mathrm{Pb} 4 f$ of the Lindlar ${ }^{34}$ catalyst.

Values of the superficial $\mathrm{Pd} / \mathrm{S}\left(\mathrm{Pd} / \mathrm{Al}\right.$ for $\mathrm{Pd} / \mathrm{Al}_{2} \mathrm{O}_{3}$ and $\mathrm{Pd} / \mathrm{Al}_{2} \mathrm{O}_{3}-\mathrm{Mg}$; $\mathrm{Pd} / \mathrm{Ca}$ for $\mathrm{Pd} / \mathrm{CaCO}_{3}$ and Lindlar) and $\mathrm{Cl} / \mathrm{Pd}(\%$ at $/$ at $)$ atomic ratios are also shown in Table 3. With respect to the $\mathrm{Pd} / \mathrm{S}$ atomic ratios as determined by XPS it is evident that the $\mathrm{Pd} / \mathrm{Al}$ ratio is ca. 4 times higher for $\mathrm{Pd} / \mathrm{Al}_{2} \mathrm{O}_{3}-\mathrm{Mg}$ in comparison to $\mathrm{Pd} / \mathrm{Al}_{2} \mathrm{O}_{3}\left(0.0063\right.$ and 0.0016 , respectively). For the $\mathrm{Pd} / \mathrm{CaCO}_{3}$ and Lindlar catalyst the $\mathrm{Pd} / \mathrm{Ca}$ atomic ratio was the highest $(0.022$ and 0.243$)$. This could be related to the differences in BET area and the very low pore volume $\left(\mathrm{V}_{\mathrm{p}}\right)$ that favor a high content of surface palladium. $\mathrm{Cl} / \mathrm{Pd}$ atomic ratios decrease in the following order: $\mathrm{Pd} / \mathrm{CaCO}_{3}>>$ $\mathrm{Pd} / \mathrm{Al}_{2} \mathrm{O}_{3}>\mathrm{Pd} / \mathrm{Al}_{2} \mathrm{O}_{3}-\mathrm{Mg}$. The residual chlorine content in the catalysts after reduction could be explained by the different superficial adsorption capacities of each support. The presence of $\mathrm{Cl}^{-}$ 
may also have some influence on the metallic dispersion, as well as on the performance of the catalysts.

According to XPS and TPR, the reduction pretreatment (1 h, $573 \mathrm{~K}$, hydrogen) would produce different surface species on each catalyst. $\quad \mathrm{Pd}^{\circ}$ on $\mathrm{Pd} / \mathrm{CaCO}_{3}$ and $\mathrm{Pd} / \mathrm{Al}_{2} \mathrm{O}_{3}-\mathrm{Mg}$. $\quad \mathrm{Pd}^{\circ}$ and $\mathrm{Pd}^{n+}$ on $\mathrm{Pd} / \mathrm{Al}_{2} \mathrm{O}_{3} \cdot \mathrm{Pd}^{\delta+}$ and $\mathrm{Pd}^{n+}$ on the Lindlar catalyst.

Figure 5 shows the XRD diffractograms of the catalysts and their corresponding database references $\left(\mathrm{Pd}, \mathrm{CaCO}_{3}\right.$ and $\left.\mathrm{Al}_{2} \mathrm{O}_{3}\right)$. For the $\mathrm{Pd} / \mathrm{Al}_{2} \mathrm{O}_{3}-\mathrm{Mg}$ and $\mathrm{Pd} / \mathrm{Al}_{2} \mathrm{O}_{3}$ samples the presence of $\gamma$-alumina characteristic peaks at maximum intensity $2 \theta=37.7^{\circ}, 45.9^{\circ}$ and $66.9^{\circ}$ is seen. $\mathrm{Pd} / \mathrm{CaCO}_{3}$ presents the characteristic peaks of the calcium carbonate, the main one being located at $2 \theta=29.4^{\circ}$. Due to the low concentration of $\mathrm{Pd}$ in all the samples $(<0.4 \mathrm{wt} \%)$, well below the detection limit of the XRD technique ( $>5 \mathrm{wt} \%$ ), the characteristic peaks of $\operatorname{Pd}(111)$ at $2 \theta=40.1^{\circ}$, $46.7^{\circ}$ and $68.2^{\circ}$ were overlapped with the peaks of the supports and the presence of $\mathrm{Pd}$ crystallites was undetectable. On the $\mathrm{Pd} / \mathrm{Al}_{2} \mathrm{O}_{3}-\mathrm{Mg}$ sample, the presence of $\mathrm{MgSO}_{4}$ precursor residues was not detected because the characteristic peaks at $2 \theta=24^{\circ}$ and $27^{\circ}$ were absent. For the Lindlar catalyst the characteristic peak of $\operatorname{Pd}(111)$ is observed at $2 \theta=40.1^{\circ}$. In spite of the very high $\mathrm{Pd}$ load $(5 \mathrm{wt} \%)$ the pattern is dominated by strong and narrow reflexes of the $\mathrm{CaCO}_{3}$ support. This is consistent with data previously reported by Tripathi et $\mathrm{al}^{67}$. 


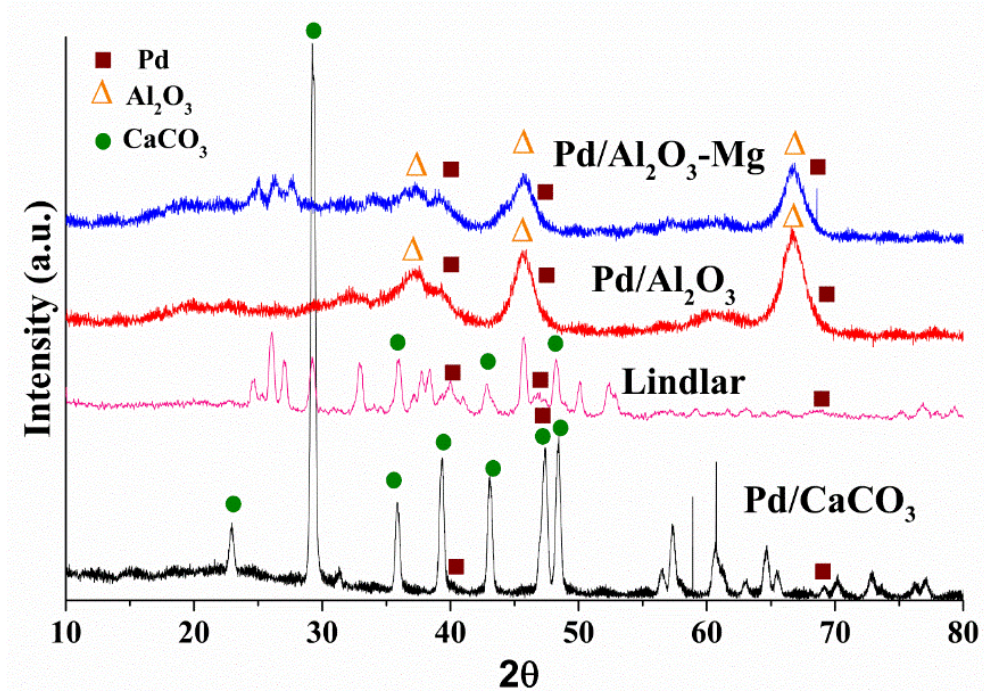

Figure 5. X-ray diffractograms of the catalysts.

\subsection{Catalytic Test}

The previous characterization analysis will allow us to correlate the properties of the synthesized catalysts with the activity and selectivity during the purification of a medium-chain olefin and during the hydrogenation of pure alkynes under mild operating conditions. The obtained results are compared with the Lindlar commercial catalyst at identical working conditions.

\subsubsection{Hydrogenation of Pure 1-Heptyne and 1-Pentyne}

Figure 6.a shows the results of total conversion of 1-heptyne $(\mathrm{X})$ as a function of time and Figure 6.b shows the selectivity to 1-heptene (S) as a function of total conversion. It can be seen that all the catalysts are active and selective at mild operational conditions, $150 \mathrm{kPa}$ and $303 \mathrm{~K}$ $\mathrm{Pd} / \mathrm{Al}_{2} \mathrm{O}_{3}$ has a very high 1 -heptyne total conversion, while $\mathrm{Pd} / \mathrm{Al}_{2} \mathrm{O}_{3}-\mathrm{Mg}, \mathrm{Pd} / \mathrm{CaCO}_{3}$ and Lindlar present very similar total conversion values, being slightly higher for $\mathrm{Pd} / \mathrm{Al}_{2} \mathrm{O}_{3}-\mathrm{Mg}$. All catalysts had high selectivity to 1-heptene ( $>80 \%)$, comparable to that of the Lindlar commercial 
one. Initially and up to $\mathrm{X}=30 \%$ the selectivity of $\mathrm{Pd} / \mathrm{Al}_{2} \mathrm{O}_{3}$ was the highest $(\geq 95 \%)$. Between $X=30-80 \%$ the selectivity begins to decrease, reaching $70 \%$ for $X=99.9 \%$. For $X$ higher than $20 \%$ the selectivity of the Lindlar catalyst $\left(\mathrm{S}=82 \%\right.$ ) was lower than the selectivity of $\mathrm{Pd} / \mathrm{Al}_{2} \mathrm{O}_{3}-$ $\mathrm{Mg}(\mathrm{S}=90 \%)$ and $\mathrm{Pd} / \mathrm{CaCO}_{3}$. This was particularly the case at $\mathrm{X}$ values higher than $90 \%$. These results show a better performance of all the synthesized catalysts in comparison to the Lindlar commercial one, or to other catalysts previously reported ${ }^{19}$ for the selective hydrogenation of 1heptyne. Lederhos et al. ${ }^{19}$ evaluated $\mathrm{Pd}, \mathrm{Pt}$ and $\mathrm{Ru}$ catalysts supported on an activated carbon (RX3, Norit) during the selective hydrogenation of 1-heptyne at the same conditions of this work: $303 \mathrm{~K}$ and $150 \mathrm{kPa}$. Pd catalysts prepared with different precursor salts, $\mathrm{PdCl}_{2}$ or $\mathrm{Pd}\left(\mathrm{NO}_{3}\right)_{2}$, were the most active and selective, reaching a total conversion of 1-heptyne at 120180 min with $85-90 \%$ selectivity. In the case of the PdClRX catalyst the authors observed that from a total conversion of ca. $80 \%$ the selectivity to 1 -heptene decreased sharply while PdNRX had a constant selectivity of $87 \%$. The differences in activity and selectivity between PdCIRX and PdNRX were attributed to several factors: a better accessibility of the alkyne to the active sites, thermodynamic factors, and electronic or steric effects of the surface groups on the activated carbon support ${ }^{19}$. 

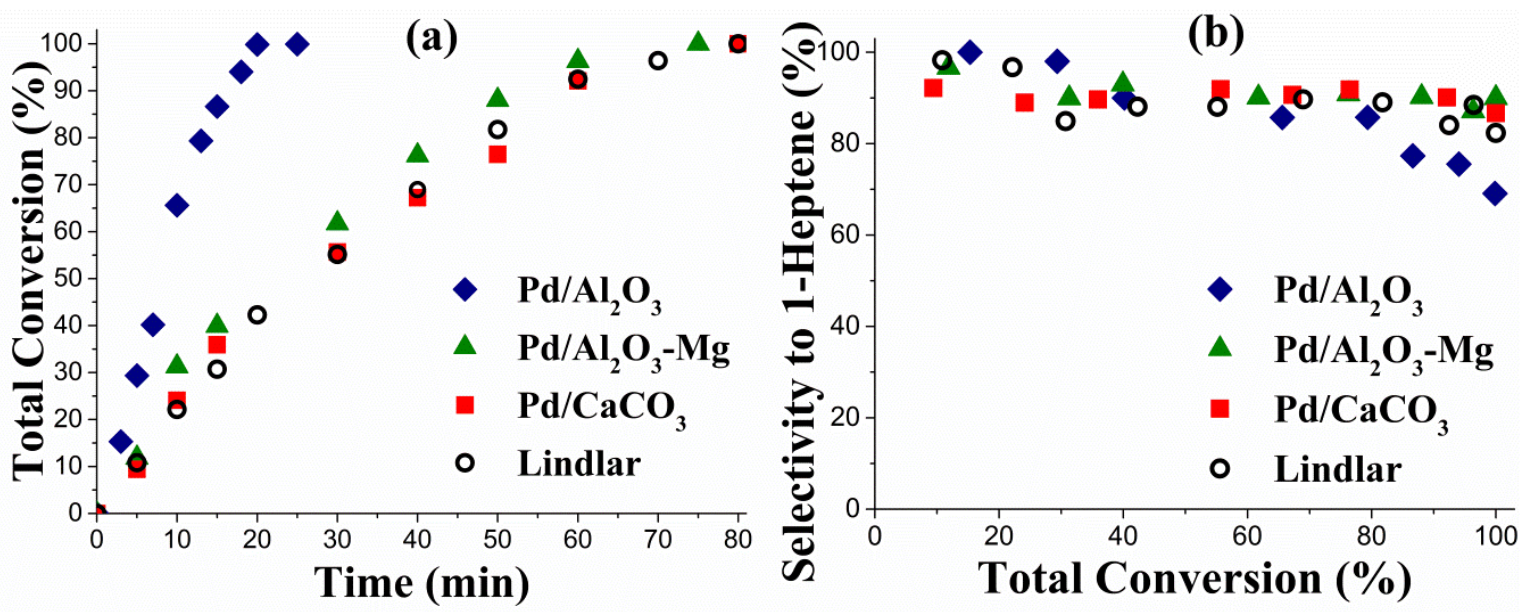

Figure 6. (a) Total Conversion of 1-Heptyne (\%) vs. Time (min) and

(b) Selectivity to 1-Heptene (\%) vs. Total Conversion (\%) for $\mathrm{Pd} / \mathrm{Al}_{2} \mathrm{O}_{3}(\diamond), \mathrm{Pd} / \mathrm{Al}_{2} \mathrm{O}_{3}-\mathrm{Mg}(\boldsymbol{\Delta})$, $\mathrm{Pd} / \mathrm{CaCO}_{3}(\square)$ and Lindlar (o).

Figure 7.a shows results of total conversion as a function of time and Figure 7.b values of selectivity to 1-pentene as a function of total conversion during the hydrogenation of 1-pentyne. The following order of 1-pentyne total conversion can be found in Figure 7.a: $\mathrm{Pd} / \mathrm{Al}_{2} \mathrm{O}_{3}>>$ $\mathrm{Pd} / \mathrm{Al}_{2} \mathrm{O}_{3}-\mathrm{Mg}>$ Lindlar $>>\mathrm{Pd} / \mathrm{CaCO}_{3}$. A comparison of Figures 6.a and 7.a shows that in all cases the hydrogenation reaction rates of 1-pentyne are greater than those of 1-heptyne. Regarding the selectivity to 1-pentene in Figure 7.b, all synthesized catalysts have very high selectivity to 1 -pentene, ca. $90 \%$, very similar to that obtained using the Lindlar commercial catalyst. 

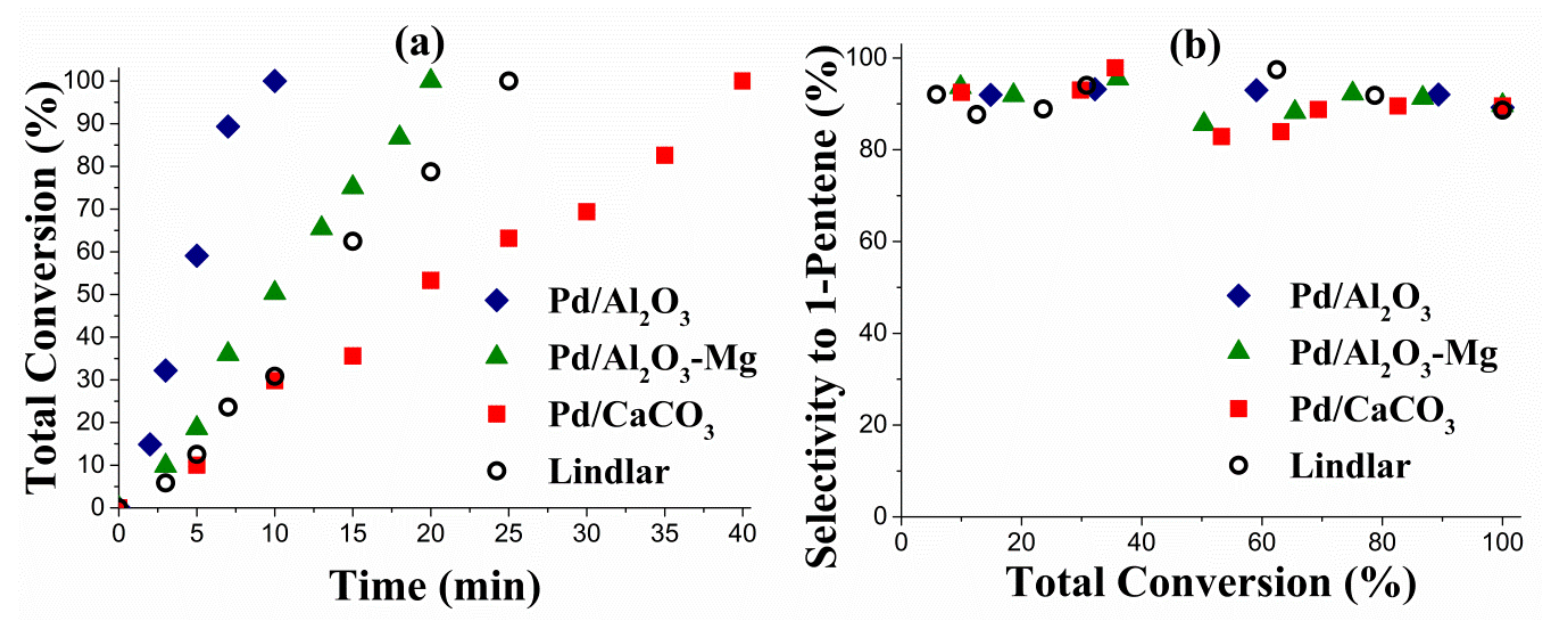

Figure 7. (a) Total Conversion of 1-Pentyne (\%) vs. Time (min) and

(b) Selectivity to 1-Pentene (\%) vs. Total Conversion (\%) for $\mathrm{Pd} / \mathrm{Al}_{2} \mathrm{O}_{3}(\diamond), \mathrm{Pd} / \mathrm{Al}_{2} \mathrm{O}_{3}-\mathrm{Mg}(\boldsymbol{\Delta})$, $\mathrm{Pd} / \mathrm{CaCO}_{3}(\square)$ and Lindlar (o).

Table 4 contains values of selectivity at the end of the run at isoconversion conditions $(\mathrm{X} \approx 99.9 \%)$ and values of the initial reaction rate (mass based $r^{0}$ and TOF) for all catalysts compared and for the different feeds used. TOF values were calculated using initial reaction rates of alkyne calculated from the data plotted in Figures 6.a and 7.a and dispersion values indicated in Table 3. The initial reaction rate of the alkynes was calculated using the following formula:

$$
r^{0}=\frac{V \cdot C^{0}}{W_{P d}} \cdot\left(\frac{\partial X}{\partial t}\right)_{t=0}
$$

$\mathrm{r}^{0}$ is the initial reaction rate of the alkyne $\left[\mathrm{mol} \mathrm{g}_{\mathrm{Pd}}{ }^{-1} \mathrm{~min}^{-1}\right] .(\partial \mathrm{X} / \partial \mathrm{t})_{\mathrm{t}=0}$ is the tangent value of the plot of alkyne total conversion versus time at $t=0 a . C^{0}$ is the initial concentration of alkyne $\left[\mathrm{mol} \mathrm{L}^{-1}\right], \mathrm{W}_{\mathrm{Pd}}$ the mass of palladium $\left[\mathrm{g}_{\mathrm{Pd}}\right], \mathrm{V}$ the reaction volume $[\mathrm{L}]$ and $\mathrm{t}$ the reaction time [min]. 
Table 4. Comparison of catalytic results.

\begin{tabular}{|c|c|c|c|c|c|c|}
\hline Catalyst & Reactant & $\begin{array}{c}\mathrm{t} \\
(\mathrm{min})\end{array}$ & $\begin{array}{c}X \\
(\%)\end{array}$ & $\begin{array}{l}* \\
(\%)\end{array}$ & $\begin{array}{c}\mathbf{r}^{0} \\
\left(\mathrm{~mol} \mathrm{~g}_{\mathrm{Pd}}{ }^{-1} \mathrm{~min}^{-1}\right)\end{array}$ & $\begin{array}{c}\text { TOF } \\
\left(\mathrm{min}^{-1}\right)\end{array}$ \\
\hline $\mathrm{Pd} / \mathrm{Al}_{2} \mathrm{O}_{3}$ & 1-Heptyne & 20 & 99.9 & 70 & 76.20 & 2.03 \\
\hline $\mathrm{Pd} / \mathrm{Al}_{2} \mathrm{O}_{3}-\mathrm{Mg}$ & 1-Heptyne & 75 & 99.9 & 90 & 33.18 & 0.90 \\
\hline $\mathrm{Pd} / \mathrm{CaCO}_{3}$ & 1-Heptyne & 80 & 99.9 & 87 & 32.41 & 1.33 \\
\hline Lindlar & 1-Heptyne & 80 & 99.9 & 82 & 28.61 & 12.18 \\
\hline $\mathrm{Pd} / \mathrm{Al}_{2} \mathrm{O}_{3}$ & 1-Pentyne & 10 & 99.9 & 86 & 155.65 & 4.14 \\
\hline $\mathrm{Pd} / \mathrm{Al}_{2} \mathrm{O}_{3}-\mathrm{Mg}$ & 1-Pentyne & 20 & 99.9 & 90 & 53.17 & 1.45 \\
\hline $\mathrm{Pd} / \mathrm{CaCO}_{3}$ & 1-Pentyne & 40 & 99.9 & 90 & 37.11 & 1.52 \\
\hline Lindlar & 1-Pentyne & 25 & 99.9 & 89 & 35.97 & 15.31 \\
\hline $\mathrm{Pd} / \mathrm{Al}_{2} \mathrm{O}_{3}$ & 1-Pentyne/1-Pentene & 18 & 99.9 & 91 & 186.64 & 4.97 \\
\hline $\mathrm{Pd} / \mathrm{Al}_{2} \mathrm{O}_{3}-\mathrm{Mg}$ & 1-Pentyne/1-Pentene & 50 & 99.9 & 93 & 41.11 & 1.12 \\
\hline $\mathrm{Pd} / \mathrm{CaCO}_{3}$ & 1-Pentyne/1-Pentene & 140 & 93.0 & 89 & 32.31 & 1.32 \\
\hline Lindlar & 1-Pentyne/1-Pentene & 30 & 99.9 & 88 & 38.72 & 16.48 \\
\hline
\end{tabular}

*Selectivity to the corresponding alkene product.

For the hydrogenation of the pure alkynes, the following initial reaction rate order is found: $\mathrm{Pd} / \mathrm{Al}_{2} \mathrm{O}_{3}>>\mathrm{Pd} / \mathrm{Al}_{2} \mathrm{O}_{3}-\mathrm{Mg} \geq \mathrm{Pd} / \mathrm{CaCO}_{3}>$ Lindlar. Besides its high activity it is important to note that $\mathrm{Pd} / \mathrm{Al}_{2} \mathrm{O}_{3}$ has the lowest selectivity to 1-heptene and 1-pentene, while the other catalysts have high selectivity to the desired alkene product, quite similar to that obtained with the Lindlar commercial catalyst. Therefore on the basis of activity and selectivity all the prepared catalysts were comparable or better than the Lindlar catalyst for hydrogenation of alkynes. The activity and selectivity results suggest a better synergism between the Pd nanoparticles and the supports, probably because of an easier dissociation of hydrogen over the metal center, as reported by Jackson et al. ${ }^{32}$ In these reaction the initial reaction rate is supposed to be related to the dissociative adsorption of hydrogen ${ }^{40}$. It is well known that during hydrogenations metallic centers rich in electrons can cleave the $\mathrm{H}-\mathrm{H}$ bond by means of the interaction of a filled $\boldsymbol{d}$ metal orbital with the empty $\sigma$ antibonding molecular orbital of $\mathrm{H}_{2}{ }^{68}$. This scission is favored on $\mathrm{Pd}^{\circ}$ 
sites with a $\boldsymbol{d}^{10}$ configuration. The adsorption of $\mathrm{H}_{2}$ would also be favored over small particles. As observed in Table 3 the $\mathrm{Pd} / \mathrm{Al}_{2} \mathrm{O}_{3}, \mathrm{Pd} / \mathrm{Al}_{2} \mathrm{O}_{3}-\mathrm{Mg}$ and- $\mathrm{Pd} / \mathrm{CaCO}_{3}$ catalysts show a high amount of $\mathrm{Pd}^{\circ}$ active species and small particle sizes. The dissociative adsorption of hydrogen and the whole catalytic cycle would then be enhanced ${ }^{69,70}$.

The high activity of the $\mathrm{Pd} / \mathrm{Al}_{2} \mathrm{O}_{3}$ catalyst can be explained by three main factors: a) electronic effects of $\mathrm{Pd}^{\circ}$ species (with $3 d \mathrm{BE}$ of $334.7 \mathrm{eV}$, as found by XPS) that can improve the dissociative cleavage of $\mathrm{H}-\mathrm{H}$ due to a high $\boldsymbol{d}^{10}$ electron availability; b) $\mathrm{Pd}^{n+}$ electrodeficient species (acid Lewis sites) favoring the adsorption of the terminal alkyne via the alkyne triple bonds (basic Lewis sites); and c) remaining Brönsted acid sites of alumina providing additional protonic hydrogen. These factors would enhance the hydrogenation rate. Factors b) and c) would also favor overhydrogenation and isomerization undesirable reactions, thus decreasing the selectivity of the $\mathrm{Pd} / \mathrm{Al}_{2} \mathrm{O}_{3}$ catalyst.

The $\mathrm{Pd} / \mathrm{Al}_{2} \mathrm{O}_{3}-\mathrm{Mg}$ is also more active than the Lindlar catalyst. Again the presence of a high concentration of $\mathrm{Pd}^{\circ}$ nanoparticles and Lewis acid sites $\left(\mathrm{MgO}-\mathrm{Al}_{2} \mathrm{O}_{3}\right.$ surface species) for adsorption of the alkyne, would explain this activity (electronic effect). The high selectivity could be related to geometrical or steric effects of cationic magnesium surface species inhibiting isomerization reactions. In turn the high selectivity of $\mathrm{Pd} / \mathrm{CaCO}_{3}$ could be assigned to the carbonate groups (soft Lewis base) preventing undesirable isomerization reactions (electronic effects). Finally the high selectivity of the Lindlar catalysts is attributed to the presence of surface lead species, which prevent isomerization reactions due to electronic effects.

It is important to note that the rate of hydrogenation of 1-pentyne is higher than that of 1heptyne because the 1-pentyne molecule is smaller. It is less inhibited by surface groups by geometrical effects both for adsorption and hydrogenation of the triple bond. The larger terminal 
alkyne can also be adsorbed either in a perpendicular or parallel way and this can hinder the interaction with the catalyst active centers ${ }^{71,72}$.

\subsubsection{Purification of 1 -pentene}

As mentioned in the Introduction the selective hydrogenation of the triple bond $(\mathrm{C} \equiv \mathrm{C})$ of alkynes in the presence of a high concentration of alkenes (double bonds) is of great importance, and especially for the purification of $\mathrm{C}_{5}$ olefinic streams, e.g. for production of polymers. In order to assess the performance in this situation, the prepared catalysts were evaluated in the reaction of purification of 1-pentene (1-pentyne/1-pentene feedstock, 30:70 \% v/v) at mild reaction conditions $(150 \mathrm{kPa}$ and $303 \mathrm{~K})$. The 1-alkyne total conversion and selectivity to 1 alkene of each catalyst were compared against those of the Lindlar commercial catalyst.

Figure 8 shows the 1-pentyne total conversion vs. time and selectivity to 1-pentene as a function of total conversion. Figure 9 shows the concentration of reactants and product as a function of time. As shown in both Figures all catalysts were active and selective for the purification of 1 -pentene. Table 4 shows values of the 1 -pentyne initial reaction rate $\left(\mathrm{r}^{0}\right.$, calculated using Eq. (II)) and the turnover frequency (TOF). The most active catalyst was $\mathrm{Pd} / \mathrm{Al}_{2} \mathrm{O}_{3}$, followed by $\mathrm{Pd} / \mathrm{Al}_{2} \mathrm{O}_{3}-\mathrm{Mg}$ and the Lindlar catalyst. The $\mathrm{Pd} / \mathrm{CaCO}_{3}$ catalyst was the least active. As shown in Figure 8 all the prepared catalysts had good selectivity to the desired product, 1-pentene, ca. $88-98 \%$. Besides, the $\mathrm{Pd} / \mathrm{Al}_{2} \mathrm{O}_{3}$ catalyst was the only one producing isomers. During the purification of alkenes, the alkyne efficiently blocks alkene re-adsorption, but some catalytic properties e.g.: acidity or particle sizes can have an influence on isomerization or overhydrogenation undesired, which are generated especially when a $30-10 \%$ of residual alkyne remains in the reactor. Small particle sizes of $\mathrm{Pd}^{\circ}$ active sites and the presence of acid 
Lewis sites (electronic effects) seem responsible for the high reaction rate of $\mathrm{Pd} / \mathrm{Al}_{2} \mathrm{O}_{3}$ and $\mathrm{Pd} / \mathrm{Al}_{2} \mathrm{O}_{3}-\mathrm{Mg}$. The Brönsted acid sites of the catalyst (electronic effect) would directly promote the isomerization reactions on $\mathrm{Pd} / \mathrm{Al}_{2} \mathrm{O}_{3}$. On the other hand weaker acid sites (electronic effect) favoring 1-pentene desorption would be responsible for the highest selectivity of $\mathrm{Pd} / \mathrm{Al}_{2} \mathrm{O}_{3}-\mathrm{Mg}$.

High dispersion was favored by the use of an ionic complex $\left[\mathrm{Pd}\left(\mathrm{NH}_{3}\right)_{4}\right]^{2+}$ at $\mathrm{pH}=10$ for the impregnation. This allowed the stabilization of Pd particles over the Brönsted acid sites of the support and prevented their agglomeration. Quesada et al. ${ }^{73}$ have demonstrated to a large extent the importance of using metallic complexes during the synthesis of catalysts for hydrogenation. In our case, the low load of the prepared Pd catalysts $(0.4 \mathrm{wt} \%)$ as compared to the high load of the Lindlar catalyst (5 wt \%) suggests the presence of a metal monolayer distribution in the prepared catalysts and a less efficient "stack" distribution in the case of the Lindlar catalyst. Electronic effects by surface $\mathrm{Pb}$ species would also modify the $\mathrm{Pd}$ active sites $\left(\mathrm{Pd}^{\delta+}\right.$ and $\left.\mathrm{Pd}^{n+}\right)$.
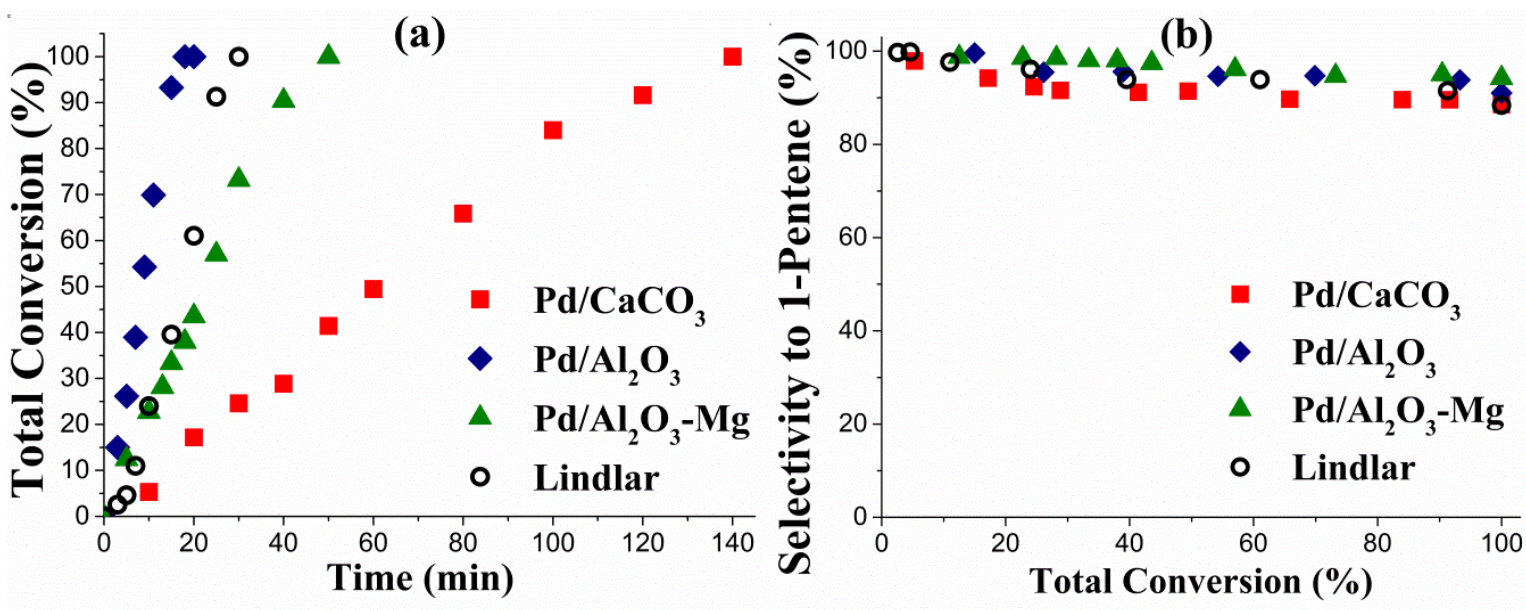

Figure 8. (a) Total Conversion of 1-Pentyne (\%) vs. Time (min), and (b) Selectivity to 1-Pentene (\%) vs. Total Conversion (\%) during the hydrogenation of the 1-Pentyne/1-Pentene mixture $(30: 70 \% \mathrm{v} / v)$, for $\mathrm{Pd} / \mathrm{Al}_{2} \mathrm{O}_{3}(\bullet), \mathrm{Pd} / \mathrm{Al}_{2} \mathrm{O}_{3}-\mathrm{Mg}(\mathbf{\Delta}), \mathrm{Pd} / \mathrm{CaCO}_{3}(\square)$ and Lindlar (०). 
The XPS and TPR results helped understanding the properties and electronic effects in the prepared catalysts. The adsorption or interaction of unsaturated olefins can be rationalized by the effects of donation and acceptance of electrons involved in the bonds ${ }^{72}$. Metals such as Pd that have high $\mathrm{H}_{2}$ chemisorption capacity are very much affected by the electronic effects of the supports $^{72}$. XPS and TPR revealed that after the reduction of the catalysts with $\mathrm{H}_{2}(1 \mathrm{~h}$ at $573 \mathrm{~K})$ $\mathrm{Pd}^{\circ}$ species were present on the surface. $\mathrm{Pd}^{\circ}$ nanoparticles would favor the dissociative adsorption of hydrogen during the catalytic tests. The TPD-Py analysis also highlighted the differences of acidity of supports and catalysts (Table 2), the type of surface acidity having a great influence on the catalytic properties. The $\mathrm{Pd} / \mathrm{Al}_{2} \mathrm{O}_{3}$ catalyst, with the highest distribution of medium acidity strength, had the highest 1-pentyne initial reaction rate, but it was the least selective, forming too much of branched alkenes. As previously stated the remaining Brönsted acid sites on alumina provide additional protonic hydrogen that increases the hydrogenation rate of 1-pentyne. These Brönsted acid sites are also responsible for the isomerization and overhydrogenation of 1-pentene. On the other side, $\mathrm{Pd} / \mathrm{Al}_{2} \mathrm{O}_{3}-\mathrm{Mg}$ was the catalyst with the highest weak acidity, a high activity and the highest alkene selectivity. Totally reduced $\mathrm{Pd}^{\circ}$ nanoparticles that favor $\mathrm{H}_{2}$ dissociative chemisorption, and superficial cationic magnesium oxide species that favor alkyne chemisorption, would both be responsible for the high activity of the $\mathrm{Pd} / \mathrm{Al}_{2} \mathrm{O}_{3}-\mathrm{Mg}$ catalyst. Its high selectivity can be explained by geometrical/steric effects of $\mathrm{MgO}-\mathrm{Al}_{2} \mathrm{O}_{3}$ surface species that would prevent isomerization. 

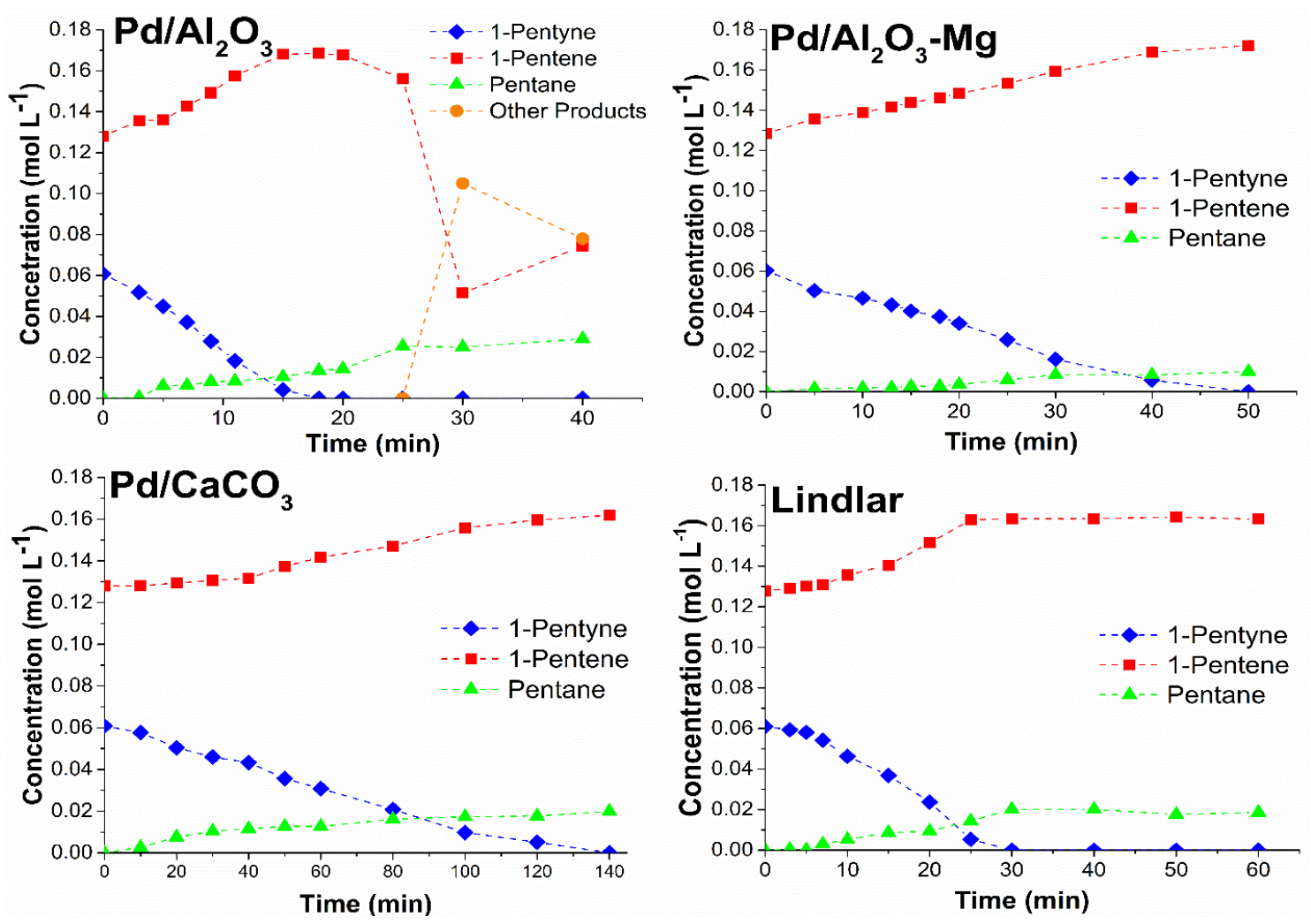

Figure 9. Concentration of reactants and products $\left(\mathrm{mol} \mathrm{L}^{-1}\right)$ as a function of time (min). Hydrogenation of a 1-Pentyne/1-Pentene mixture $(30: 70 \mathrm{v} / \mathrm{v})$.

$\mathrm{Pd} / \mathrm{CaCO}_{3}$ catalyst was an active and selective catalyst with significant results in the selective hydrogenation of alkynes; its activity and selectivity is comparable to that of Lindlar commercial catalyst. However its initial reaction rate was the lowest if compared to the $\mathrm{Pd} / \mathrm{Al}_{2} \mathrm{O}_{3}$ or $\mathrm{Pd} / \mathrm{Al}_{2} \mathrm{O}_{3}-\mathrm{Mg}$ catalysts. The lower activity can be partly attributed to its low acidity, with weak and medium acid sites being more abundant. This acid distribution could however be beneficial to the selectivity. Furthermore it should be noted that the presence of a big amount of $\mathrm{Cl}^{-}$on the surface can induce electronic effects. Jackson et al ${ }^{32}$ have indicated that residual chloride weakens the bond of surface terminal alkynes and decreases its reactivity. Badano et al. ${ }^{61}$ have reported that the presence of $\mathrm{Cl}^{-}$greatly improves the selectivity and resistance to sulfur 
poisoning. Therefore the low initial reaction rate of $\mathrm{Pd} / \mathrm{CaCO}_{3}$ could be explained by two factors. First, by the low adsorption capacity of the carbonate support due to the weak electronic interaction between the surface calcium cationic species (hard Lewis acid) and the $\pi$ electron of alkyne (soft Lewis base). Second, by the high surface concentration of electronegative chloride species that inhibits the adsorption of the alkyne (electronic effects). The high selectivity of $\mathrm{Pd} / \mathrm{CaCO}_{3}$ can be attributed to the presence of carbonate groups (soft Lewis base) that prevent the undesirable isomerization (electronic effect).

Taking into account the above results, on the basis of its high activity and selectivity ( $>90$ $\%$, the best catalyst for the purification of alkenes and/or the hydrogenation of pure terminal alkynes is the low loaded $\mathrm{Pd} / \mathrm{Al}_{2} \mathrm{O}_{3}-\mathrm{Mg}$. $\mathrm{Pd} / \mathrm{CaCO}_{3}$ is also a promising catalyst and could be the second choice, because it has a high selectivity $(>89 \%)$, similar to that of the Lindlar catalyst $(>88 \%)$.

\section{Conclusions}

Low-loaded $\mathrm{Pd} / \mathrm{Al}_{2} \mathrm{O}_{3}, \mathrm{Pd} / \mathrm{Al}_{2} \mathrm{O}_{3}-\mathrm{Mg}$ and $\mathrm{Pd} / \mathrm{CaCO}_{3}$ catalysts were prepared using chloride of tetraamminepalladium(II) as precursor solution. Highly dispersed Pd nanoparticles were obtained with an average particle size ca. $3-4.5 \mathrm{~nm}$. These catalysts were evaluated with the purification of a $\mathrm{C}_{5}$ olefin and with the selective hydrogenation of different medium chain terminal pure alkynes $\left(\mathrm{C}_{7}\right.$ and $\left.\mathrm{C}_{5}\right)$. Lindlar commercial catalyst was used as reference.

The synthetized catalysts were characterized by ICP-AES, $\mathrm{N}_{2}$ adsorption/desorption isotherm, TPD-Py, XRD, $\mathrm{H}_{2}$-TPR, TEM and XPS.

TPD-Py results revealed different acidity distributions and suggested the adsorption of $\left[\operatorname{Pd}\left(\mathrm{NH}_{3}\right)_{4}\right]^{2+}$ over the Brönsted acid sites of alumina (Mg-free or Mg-doped) and over 
superficial carbonate anions (Lewis base). The order of total acidity and weak acidity was the same: $\mathrm{Pd} / \mathrm{Al}_{2} \mathrm{O}_{3}-\mathrm{Mg}>>\mathrm{Pd} / \mathrm{Al}_{2} \mathrm{O}_{3} \gg>$ Lindlar $>\mathrm{Pd} / \mathrm{CaCO}_{3} . \mathrm{Pd} / \mathrm{Al}_{2} \mathrm{O}_{3}$ had more mild acid sites.

XPS analysis revealed that all the prepared catalysts had a high concentration of $\mathrm{Pd}^{\circ}$ nanoparticles.

The results of purification of 1-pentene and hydrogenation of 1-heptyne or 1-pentyne, at mild reaction conditions, showed that all the prepared catalysts were very active and highly selective to the 1-alkene product. Selectivity values were indeed higher than those of the Lindlar commercial catalyst.

$\mathrm{Pd} / \mathrm{Al}_{2} \mathrm{O}_{3}$ was the most active but the least selective catalyst. This was attributed to Brönsted acid sites of medium strength providing additional protonic hydrogen, positively increasing the hydrogenation rate of 1-alkyne but negatively promoting the isomerization and overhydrogenation of the terminal alkene. $\mathrm{Pd} / \mathrm{Al}_{2} \mathrm{O}_{3}-\mathrm{Mg}$, showed a high activity and the highest selectivity to the corresponding alkene. This was attributed to the presence of $\mathrm{Pd}^{\circ}$ nanoparticles promoting the dissociative adsorption of hydrogen and surface $\mathrm{MgO}-\mathrm{Al}_{2} \mathrm{O}_{3}$ species promoting the adsorption of the alkyne (electronic effects) and preventing isomerization (geometrical/steric effects).

Low-loaded $\mathrm{Pd} / \mathrm{Al}_{2} \mathrm{O}_{3}-\mathrm{Mg}$ and $\mathrm{Pd} / \mathrm{CaCO}_{3}$ catalysts can be used for the purification of medium or large terminal alkenes at mild reaction conditions as an alternative to the high loaded Lindlar commercial catalyst.

\section{Acknowledgment}

The financial support provided by UNL (Grants CAI+D 50420150100074LI and 50420150100028LI), CONICET (Grant PIP 11220130100457CO) and ANPCyT (Grant PICT 
2016 1453) are acknowledged.

\section{References}

1. Dobson, N. A.; Eglinton, G.; Krishnamurti, M.; Raphael, R. A.; Willis, R. G., Selective catalytic hydrogenation of acetylenes. Tetrahedron 1961, 16 (1), 16-24.

2. Thomas, S. P.; Greenhalgh, M. D., 8.16 Heterogeneous Hydrogenation of CC and CC Bonds A2 - Knochel, Paul. In Comprehensive Organic Synthesis II (Second Edition), Elsevier: Amsterdam, 2014; pp 564-604.

3. Carey, F. A.; Sundberg, R. J., Advanced Organic Chemistry. Springer US: 2000.

4. Lebel, H.; Paquet, V., Multicatalytic Processes Using Diverse Transition Metals for the Synthesis of Alkenes. Journal of the American Chemical Society 2004, 126 (36), 11152-11153.

5. Sadrameli, S. M., Thermal/catalytic cracking of hydrocarbons for the production of olefins: A state-of-the-art review I: Thermal cracking review. Fuel 2015, 140, 102-115.

6. McCue, A. J.; Guerrero-Ruiz, A.; Ramirez-Barria, C.; Rodríguez-Ramos, I.; Anderson, J. A., Selective hydrogenation of mixed alkyne/alkene streams at elevated pressure over a palladium sulfide catalyst. Journal of Catalysis 2017, 355 (Supplement C), 40-52.

7. Ji, Y.; Yang, H.; Yan, W., Catalytic cracking of n-hexane to light alkene over ZSM-5 zeolite: Influence of hierarchical porosity and acid property. Molecular Catalysis 2018, 448, 9199.

8. Ramsurn, H.; Gupta, R. B., Chapter 15 - Hydrogenation by Nanoparticle Catalysts A2 Suib, Steven L. In New and Future Developments in Catalysis, Elsevier: Amsterdam, 2013; pp 347-374.

9. Blaser, H.-U.; Schnyder, A.; Steiner, H.; Rössler, F.; Baumeister, P., Selective Hydrogenation of Functionalized Hydrocarbons. In Handbook of Heterogeneous Catalysis, Wiley-VCH Verlag GmbH \& Co. KGaA: 2008.

10. Chen, B.; Dingerdissen, U.; Krauter, J. G. E.; Lansink Rotgerink, H. G. J.; Möbus, K.; Ostgard, D. J.; Panster, P.; Riermeier, T. H.; Seebald, S.; Tacke, T.; Trauthwein, H., New developments in hydrogenation catalysis particularly in synthesis of fine and intermediate chemicals. Applied Catalysis A: General 2005, 280 (1), 17-46.

11. Segura, Y.; López, N.; Pérez-Ramírez, J., Origin of the superior hydrogenation selectivity of gold nanoparticles in alkyne + alkene mixtures: Triple- versus double-bond activation. Journal of Catalysis 2007, 247 (2), 383-386.

12. McCue, A. J.; Gibson, A.; Anderson, J. A., Palladium assisted copper/alumina catalysts for the selective hydrogenation of propyne, propadiene and propene mixed feeds. Chemical Engineering Journal 2016, 285 (Supplement C), 384-391.

13. Lopez, N.; Vargas-Fuentes, C., Promoters in the hydrogenation of alkynes in mixtures: insights from density functional theory. Chemical Communications 2012, 48 (10), 1379-1391.

14. Insorn, P.; Kitiyanan, B., Selective hydrogenation of mixed C4 containing high vinyl acetylene by Mn-Pd, Ni-Pd and Ag-Pd on Al2O3 catalysts. Catalysis Today 2015, 256, 223-230. 15. Bazzazzadegan, H.; Kazemeini, M.; Rashidi, A. M., A high performance multi-walled carbon nanotube-supported palladium catalyst in selective hydrogenation of acetylene-ethylene mixtures. Applied Catalysis A: General 2011, 399 (1), 184-190. 
16. Benavidez, A. D.; Burton, P. D.; Nogales, J. L.; Jenkins, A. R.; Ivanov, S. A.; Miller, J. T.; Karim, A. M.; Datye, A. K., Improved selectivity of carbon-supported palladium catalysts for the hydrogenation of acetylene in excess ethylene. Applied Catalysis A: General 2014, 482, 108-115.

17. Ibhadon AO, K. S., The Reduction of Alkynes Over Pd-Based Catalyst Materials- A Pathway to Chemical Synthesis. Journal of Chemical Engineering \& Process Technology 2018, $9(2), 376$.

18. Tew, M. W.; Janousch, M.; Huthwelker, T.; van Bokhoven, J. A., The roles of carbide and hydride in oxide-supported palladium nanoparticles for alkyne hydrogenation. Journal of Catalysis 2011, 283 (1), 45-54.

19. Lederhos, C. R.; Badano, J. M.; Carrara, N.; Coloma-Pascual, F.; Almansa, M. C.; Liprandi, D.; Quiroga, M., Metal and Precursor Effect during 1-Heptyne Selective Hydrogenation Using an Activated Carbon as Support. The Scientific World Journal 2013, 2013, 9.

20. Nikoshvili, L. Z.; Makarova, A. S.; Lyubimova, N. A.; Bykov, A. V.; Sidorov, A. I.; Tyamina, I. Y.; Matveeva, V. G.; Sulman, E. M., Kinetic study of selective hydrogenation of 2methyl-3-butyn-2-ol over Pd-containing hypercrosslinked polystyrene. Catalysis Today 2015, 256, 231-240.

21. Werner Bonrath, J. M., Jan Schütz, Bettina Wüstenberg, T. N., Hydrogenation in the Vitamins and Fine Chemicals Industry - An Overview. InTech, 2012, Hydrogenation., 66-90. 22. Al-Herz, M.; Simmons, M. J. H.; Wood, J., Selective Hydrogenation of 1-Heptyne in a Mini Trickle Bed Reactor. Industrial \& Engineering Chemistry Research 2012, 51 (26), 8815 8825.

23. Kittisakmontree, P.; Yoshida, H.; Fujita, S.-i.; Arai, M.; Panpranot, J., The effect of $\mathrm{TiO} 2$ particle size on the characteristics of $\mathrm{Au}-\mathrm{Pd} / \mathrm{TiO} 2$ catalysts. Catalysis Communications 2015, 58, 70-75.

24. Garcia, P. E.; Lynch, A. S.; Monaghan, A.; Jackson, S. D., Using modifiers to specify stereochemistry and enhance selectivity and activity in palladium-catalysed, liquid phase hydrogenation of alkynes. Catalysis Today 2011, 164 (1), 548-551.

25. Nijhuis, T. A.; van Koten, G.; Moulijn, J. A., Optimized palladium catalyst systems for the selective liquid-phase hydrogenation of functionalyzed alkynes. Applied Catalysis A:

General 2003, 238 (2), 259-271.

26. Crespo-Quesada, M.; Yarulin, A.; Jin, M.; Xia, Y.; Kiwi-Minsker, L., Structure Sensitivity of Alkynol Hydrogenation on Shape- and Size-Controlled Palladium Nanocrystals: Which Sites Are Most Active and Selective? Journal of the American Chemical Society 2011, 133 (32), 12787-12794.

27. Hu, J.; Zhou, Z.; Zhang, R.; Li, L.; Cheng, Z., Selective hydrogenation of phenylacetylene over a nano-Pd/ $\alpha-\mathrm{A} 12 \mathrm{O} 3$ catalyst. Journal of Molecular Catalysis A: Chemical 2014, 381, 61-69.

28. Mastalir, Á.; Király, Z.; Szöllösi, G.; Bartók, M., Stereoselective hydrogenation of 1phenyl-1-pentyne over low-loaded Pd-montmorillonite catalysts. Applied Catalysis A: General 2001, 213 (1), 133-140.

29. Canning, A. S.; Jackson, S. D.; Monaghan, A.; Wright, T., C-5 alkene hydrogenation: Effect of competitive reactions on activity and selectivity. Catalysis Today 2006, 116 (1), 22-29. 30. Hamilton, C. A.; Jackson, S. D.; Kelly, G. J.; Spence, R.; de Bruin, D., Competitive reactions in alkyne hydrogenation. Applied Catalysis A: General 2002, 237 (1), 201-209. 
31. Jackson, S. D.; Shaw, L. A., The liquid-phase hydrogenation of phenyl acetylene and styrene on a palladium/carbon catalyst. Applied Catalysis A: General 1996, 134 (1), 91-99. 32. Jackson, S. D.; Hamilton, C. A.; Kelly, G. J.; de Bruin, D., The Hydrogenation of c-5 Alkynes over Palladium Catalysts. Reaction Kinetics and Catalysis Letters 2001, 73 (1), 77-82. 33. Murugesan, K.; Alshammari, A. S.; Sohail, M.; Beller, M.; Jagadeesh, R. V., Monodisperse nickel-nanoparticles for stereo- and chemoselective hydrogenation of alkynes to alkenes. Journal of Catalysis 2019, 370, 372-377.

34. Maccarrone, M. J.; Lederhos, C. R.; Torres, G.; Betti, C.; Coloma-Pascual, F.; Quiroga, M. E.; Yori, J. C., Partial hydrogenation of 3-hexyne over low-loaded palladium mono and bimetallic catalysts. Applied Catalysis A: General 2012, 441-442, 90-98.

35. Lederhos, C. R.; Badano, J. M.; Quiroga, M. E.; L'Argentière, P. C.; Coloma-Pascual, F., Influence of ni addition to a low-loaded palladium catalyst on the selective hydrogenation of 1-heptyne. Química Nova 2010, 33, 816-820.

36. Mäki-Arvela, P.; Murzin, D. Y., Effect of catalyst synthesis parameters on the metal particle size. Applied Catalysis A: General 2013, 451, 251-281.

37. Liu, Y.; Zhao, J.; He, Y.; Feng, J.; Wu, T.; Li, D., Highly efficient PdAg catalyst using a reducible Mg-Ti mixed oxide for selective hydrogenation of acetylene: Role of acidic and basic sites. Journal of Catalysis 2017, 348, 135-145.

38. Lindlar, H.; Dubuis, R., Palladium Catalyst for Partial Reduction of Acetylenes. In Organic Syntheses, John Wiley \& Sons, Inc.: 2003.

39. Lindlar, H., Ein neuer Katalysator für selektive Hydrierungen. Helvetica Chimica Acta 1952, 35 (2), 446-450.

40. He, Y.; Fan, J.; Feng, J.; Luo, C.; Yang, P.; Li, D., Pd nanoparticles on hydrotalcite as an efficient catalyst for partial hydrogenation of acetylene: Effect of support acidic and basic properties. Journal of Catalysis 2015, 331, 118-127.

41. Maccarrone, M. J.; Torres, G. C.; Lederhos, C.; Betti, C.; Badano, J. M.; Quiroga, M. n.; Yori, J., Kinetic Study of the Partial Hydrogenation of 1-Heptyne over Ni and Pd Supported on Alumina. In Hydrogenation, Karamé, I., Ed. InTech: Rijeka, 2012; p Ch. 07.

42. Cao, Y.; Sui, Z.; Zhu, Y.; Zhou, X.; Chen, D., Selective Hydrogenation of Acetylene over Pd-In/A12O3 Catalyst: Promotional Effect of Indium and Composition-Dependent Performance. ACS Catalysis 2017, 7 (11), 7835-7846.

43. Anderson, J. A.; Mellor, J.; Wells, R. P. K., Pd catalysed hexyne hydrogenation modified by $\mathrm{Bi}$ and by $\mathrm{Pb}$. Journal of Catalysis 2009, 261 (2), 208-216.

44. Lederhos, C. R.; L'Argentière, P. C.; Fígoli, N. S., 1-Heptyne Selective Hydrogenation over Pd Supported Catalysts. Industrial \& Engineering Chemistry Research 2005, 44 (6), 17521756.

45. Silva, F. P. d.; Rossi, L. M., Palladium on magnetite: magnetically recoverable catalyst for selective hydrogenation of acetylenic to olefinic compounds. Tetrahedron 2014, 70 (20), 3314-3318.

46. Boronoev, M. P.; Zolotukhina, A. V.; Ignatyeva, V. I.; Terenina, M. V.; Maximov, A. L.; Karakhanov, E. A., Palladium Catalysts Based on Mesoporous Organic Materials in Semihydrogenation of Alkynes. Macromolecular Symposia 2016, 363 (1), 57-63.

47. Liprandi, D. A.; Cagnola, E. A.; Quiroga, M. E.; L'Argentière, P. C., Influence of the Reaction Temperature on the 3-Hexyne Semi-Hydrogenation Catalyzed by a Palladium(II) Complex. Catalysis Letters 2009, 128 (3), 423-433. 
48. Furukawa, S.; Komatsu, T., Selective Hydrogenation of Functionalized Alkynes to (E)Alkenes, Using Ordered Alloys as Catalysts. ACS Catalysis 2016, 6 (3), 2121-2125.

49. Liprandi, D.; Quiroga, M.; Cagnola, E.; L'Argentière, P., A New More Sulfur-Resistant Rhodium Complex as an Alternative to the Traditional Wilkinson's Catalyst. Industrial \& Engineering Chemistry Research 2002, 41 (19), 4906-4910.

50. Semagina, N.; Grasemann, M.; Xanthopoulos, N.; Renken, A.; Kiwi-Minsker, L., Structured catalyst of $\mathrm{Pd} / \mathrm{ZnO}$ on sintered metal fibers for 2-methyl-3-butyn-2-ol selective hydrogenation. Journal of Catalysis 2007, 251 (1), 213-222.

51. Sadeghpour, P.; Haghighi, M., High-temperature and short-time hydrothermal fabrication of nanostructured ZSM-5 catalyst with suitable pore geometry and strong intrinsic acidity used in methanol to light olefins conversion. Advanced Powder Technology 2018, 29 (5), 1175-1188.

52. Asthana, S.; Samanta, C.; Bhaumik, A.; Banerjee, B.; Voolapalli, R. K.; Saha, B., Direct synthesis of dimethyl ether from syngas over $\mathrm{Cu}$-based catalysts: Enhanced selectivity in the presence of MgO. Journal of Catalysis 2016, 334, 89-101.

53. Auroux, A.; Monaci, R.; Rombi, E.; Solinas, V.; Sorrentino, A.; Santacesaria, E., Acid sites investigation of simple and mixed oxides by TPD and microcalorimetric techniques.

Thermochimica Acta 2001, 379 (1), 227-231.

54. Topsøe, N.-Y.; Pedersen, K.; Derouane, E. G., Infrared and temperature-programmed desorption study of the acidic properties of ZSM-5-type zeolites. Journal of Catalysis 1981, 70 (1), 41-52.

55. Zakaria, Z. Y.; Linnekoski, J.; Amin, N. A. S., Catalyst screening for conversion of glycerol to light olefins. Chemical Engineering Journal 2012, 207-208, 803-813.

56. Feng, J.-T.; Ma, X.-Y.; Evans, D. G.; Li, D.-Q., Enhancement of Metal Dispersion and Selective Acetylene Hydrogenation Catalytic Properties of a Supported Pd Catalyst. Industrial \& Engineering Chemistry Research 2011, 50 (4), 1947-1954.

57. Ma, X.-Y.; Chai, Y.-Y.; Evans, D. G.; Li, D.-Q.; Feng, J.-T., Preparation and Selective Acetylene Hydrogenation Catalytic Properties of Supported Pd Catalyst by the in Situ Precipitation-Reduction Method. The Journal of Physical Chemistry C 2011, 115 (17), 86938701.

58. Brunelle, J. P., Preparation of catalysts by metallic complex adsorption on mineral oxides. In Pure and Applied Chemistry, 1978; Vol. 50, p 1211.

59. Paryjczak, T.; Szymura, J. A., Electron microscopic and chemisorption comparison studies on the metal dispersion of $\mathrm{Pd}, \mathrm{Rh}$, and Ir supported catalysts. Zeitschrift für anorganische und allgemeine Chemie 1979, 449 (1), 105-114.

60. Ferrer, V.; Moronta, A.; Sánchez, J.; Solano, R.; Bernal, S.; Finol, D., Effect of the reduction temperature on the catalytic activity of Pd-supported catalysts. Catalysis Today 2005, 107-108, 487-492.

61. Badano, J. M.; Quiroga, M.; Betti, C.; Vera, C.; Canavese, S.; Coloma-Pascual, F., Resistance to Sulfur and Oxygenated Compounds of Supported Pd, Pt, Rh, Ru Catalysts.

Catalysis Letters 2010, 137 (1), 35-44.

62. Scheidema, M. N.; Taskinen, P., Decomposition Thermodynamics of Magnesium Sulfate. Industrial \& Engineering Chemistry Research 2011, 50 (16), 9550-9556.

63. L'Vov, B. V., Mechanism of thermal decomposition of alkaline-earth carbonates. Thermochimica Acta 1997, 303 (2), 161-170. 
64. Padeste, C.; Reller, A.; Oswald, H. R., The influence of transition metals on the thermal decomposition of calcium carbonate in hydrogen. Materials Research Bulletin 1990, 25 (10), 1299-1305.

65. Wagner, C. D.; Muilenberg, G. E., Handbook of X-ray Photoelectron Spectroscopy: A Reference Book of Standard Data for Use in X-ray Photoelectron Spectroscopy. Perkin-Elmer: 1979.

66. NIST X-ray photoelectron spectroscopy database NIST standard reference database 20, Version 3.5 (Web version), National Institute of Standards and Technology, USA, 2007.

67. Tripathi, B.; Paniwnyk, L.; Cherkasov, N.; Ibhadon, A. O.; Lana-Villarreal, T.;

Gómez, R., Ultrasound-assisted selective hydrogenation of C-5 acetylene alcohols with Lindlar catalysts. Ultrasonics Sonochemistry 2015, 26, 445-451.

68. D.F. Shriver; Atkins, P. W.; Langford, C. H., Inorganic Chemistry. 3rd ed ed.; New York, 1994.

69. Markov, P. V.; Turova, O. V.; Mashkovsky, I. S.; Khudorozhkov, A. K.; Bukhtiyarov, V. I.; Stakheev, A. Y., Size effect in the liquid phase semihydrogenation of substituted alkynes over supported Pd/A12O3 catalysts. Mendeleev Communications 2015, 25 (5), 367-369.

70. Zhang, H.; Yang, Y.; Dai, W.; Lu, S.; Yu, H.; Ji, Y., Size-controlled Pd Nanoparticles Supported on $\alpha$-A12O3 as Heterogeneous Catalyst for Selective Hydrogenation of Acetylene. Chinese Journal of Chemical Engineering 2014, 22 (5), 516-521.

71. Vilé, G.; Almora-Barrios, N.; Mitchell, S.; López, N.; Pérez-Ramírez, J., From the Lindlar Catalyst to Supported Ligand-Modified Palladium Nanoparticles: Selectivity Patterns and Accessibility Constraints in the Continuous-Flow Three-Phase Hydrogenation of Acetylenic Compounds. Chemistry - A European Journal 2014, 20 (20), 5926-5937.

72. Teschner, D.; Vass, E.; Hävecker, M.; Zafeiratos, S.; Schnörch, P.; Sauer, H.; KnopGericke, A.; Schlögl, R.; Chamam, M.; Wootsch, A.; Canning, A. S.; Gamman, J. J.;

Jackson, S. D.; McGregor, J.; Gladden, L. F., Alkyne hydrogenation over Pd catalysts: A new paradigm. Journal of Catalysis 2006, 242 (1), 26-37.

73. Crespo-Quesada, M.; Dykeman, R. R.; Laurenczy, G.; Dyson, P. J.; Kiwi-Minsker, L., Supported nitrogen-modified Pd nanoparticles for the selective hydrogenation of 1-hexyne. Journal of Catalysis 2011, 279 (1), 66-74. 


\section{Caption to Figures}

Figure 1. TPD-Py results. a) Supports. b) Catalysts.

Figure 2. TEM images and particle size distribution of the catalysts.

Figure 3. $\mathrm{H}_{2}-\mathrm{TPR}$ traces of $\mathrm{Pd} / \mathrm{Al}_{2} \mathrm{O}_{3}, \mathrm{Pd} / \mathrm{Al}_{2} \mathrm{O}_{3}-\mathrm{Mg}$ and $\mathrm{Pd} / \mathrm{CaCO}_{3}$.

Figure 4. XPS spectra of the $\mathrm{Pd} 3 d$ region of all catalysts. $\mathrm{Mg} 2 p$ of $\mathrm{Pd} / \mathrm{Al}_{2} \mathrm{O}_{3}-\mathrm{Mg}$. $\mathrm{Pb} 4 f$ of the Lindlar $^{34}$ catalyst.

Figure 5. X-ray diffractograms of the catalysts.

Figure 6. (a) Total Conversion of 1-Heptyne (\%) vs. Time (min) and (b) Selectivity to 1Heptene (\%) vs. Total Conversion (\%) for $\mathrm{Pd} / \mathrm{Al}_{2} \mathrm{O}_{3}(\diamond), \mathrm{Pd} / \mathrm{Al}_{2} \mathrm{O}_{3}-\mathrm{Mg}(\boldsymbol{\Delta}), \mathrm{Pd} / \mathrm{CaCO}_{3}(\square)$ and Lindlar (०).

Figure 7. (a) Total Conversion of 1-Pentyne (\%) vs. Time (min) and (b) Selectivity to 1-Pentene (\%) vs. Total Conversion (\%) for $\mathrm{Pd} / \mathrm{Al}_{2} \mathrm{O}_{3}(\diamond), \mathrm{Pd} / \mathrm{Al}_{2} \mathrm{O}_{3}-\mathrm{Mg}(\boldsymbol{\Delta}), \mathrm{Pd} / \mathrm{CaCO}_{3}(\boldsymbol{\square})$ and Lindlar $(0)$.

Figure 8. (a) Total Conversion of 1-Pentyne (\%) vs. Time (min), and (b) Selectivity to 1-Pentene $(\%)$ vs. Total Conversion (\%) during the hydrogenation of the 1-Pentyne/1-Pentene mixture $(30: 70 \% \mathrm{v} / \mathrm{v})$, for $\mathrm{Pd} / \mathrm{Al}_{2} \mathrm{O}_{3}(\diamond), \mathrm{Pd} \mathrm{Al}_{2} \mathrm{O}_{3}-\mathrm{Mg}(\boldsymbol{\Delta}), \mathrm{Pd} / \mathrm{CaCO}_{3}(\boldsymbol{\square})$ and Lindlar $(\circ)$.

Figure 9. Concentration of reactants and products $\left(\mathrm{mol} \mathrm{L} \mathrm{L}^{-1}\right)$ as a function of time (min). Hydrogenation of a 1-Pentyne/1-Pentene mixture $(30: 70 \mathrm{v} / \mathrm{v})$.

Scheme 1. Schematic drawing of simultaneous proton and ion-exchange on alumina Brönsted sites during $\mathrm{MgSO}_{4}$ impregnation.

Scheme 2. Schematic drawing of simultaneous proton and ion-exchange on alumina free or modified during the impregnation of $\left[\mathrm{Pd}\left(\mathrm{NH}_{3}\right)_{4}\right]^{2+}$ in ammonia media. 


\section{Caption to Tables}

Table 1. Results of $\mathrm{N}_{2}$ physisorption isotherms of supports

Table 2. TPD-Py results.

Table 3. Metal loading as determined by ICP. Average particle size $\left(d_{T E M}\right)$ and dispersion $(D)$ from TEM microscopy. XPS results.

Table 4. Comparison of catalytic results. 


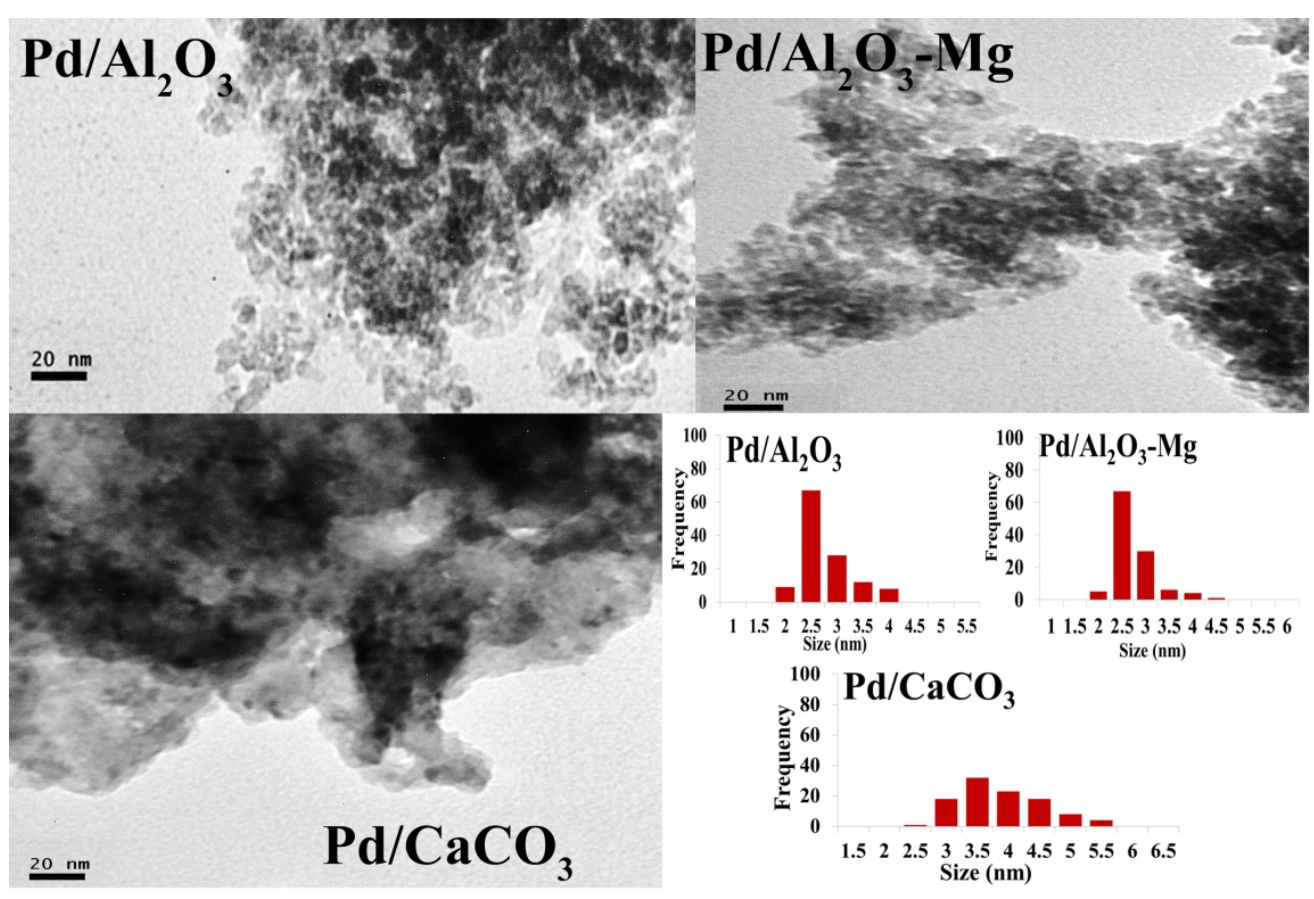

Figure 2.

$254 \times 170 \mathrm{~mm}(300 \times 300$ DPI $)$ 

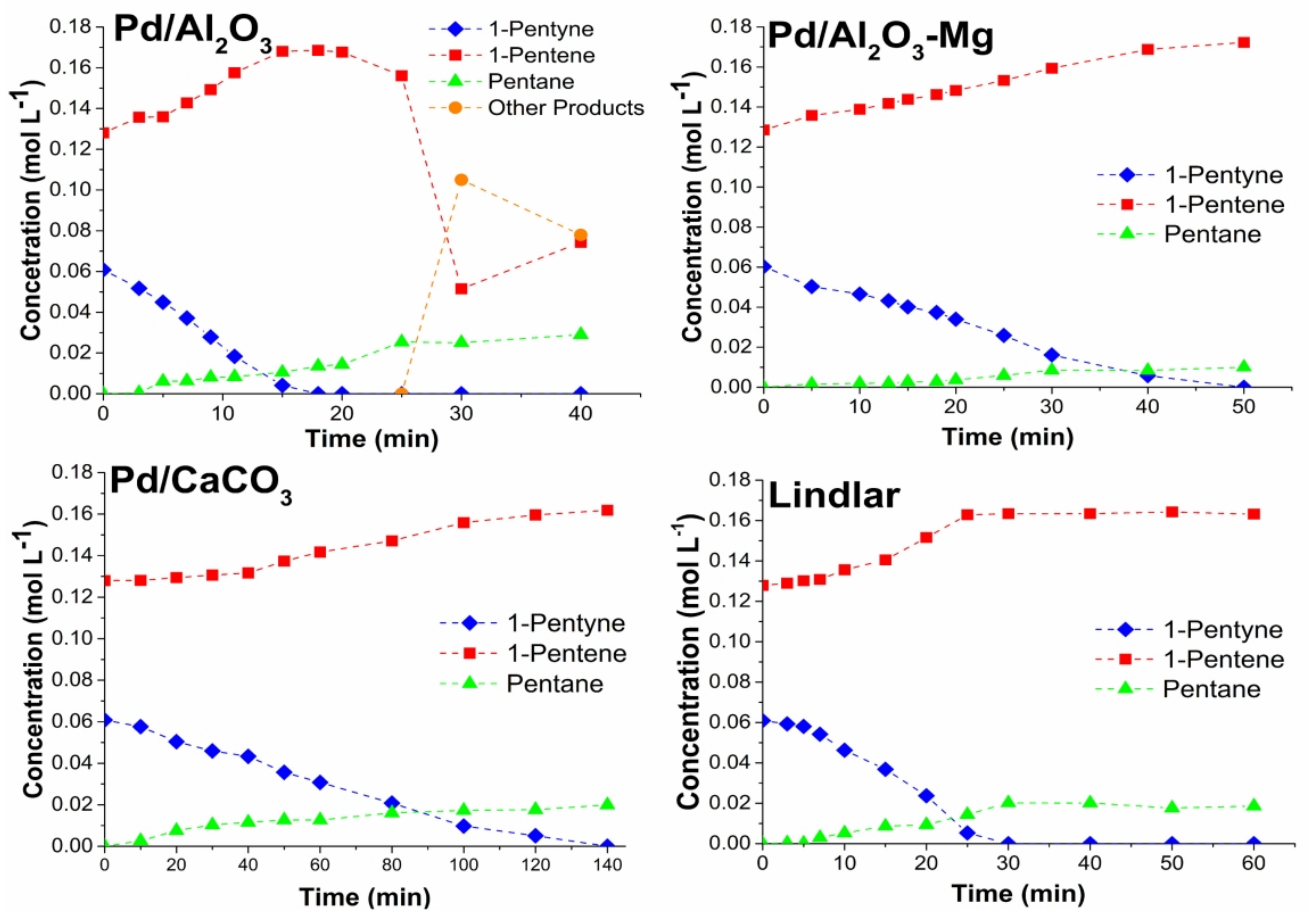

Figura 9.

$254 \times 177 \mathrm{~mm}(300 \times 300 \mathrm{DPI})$ 


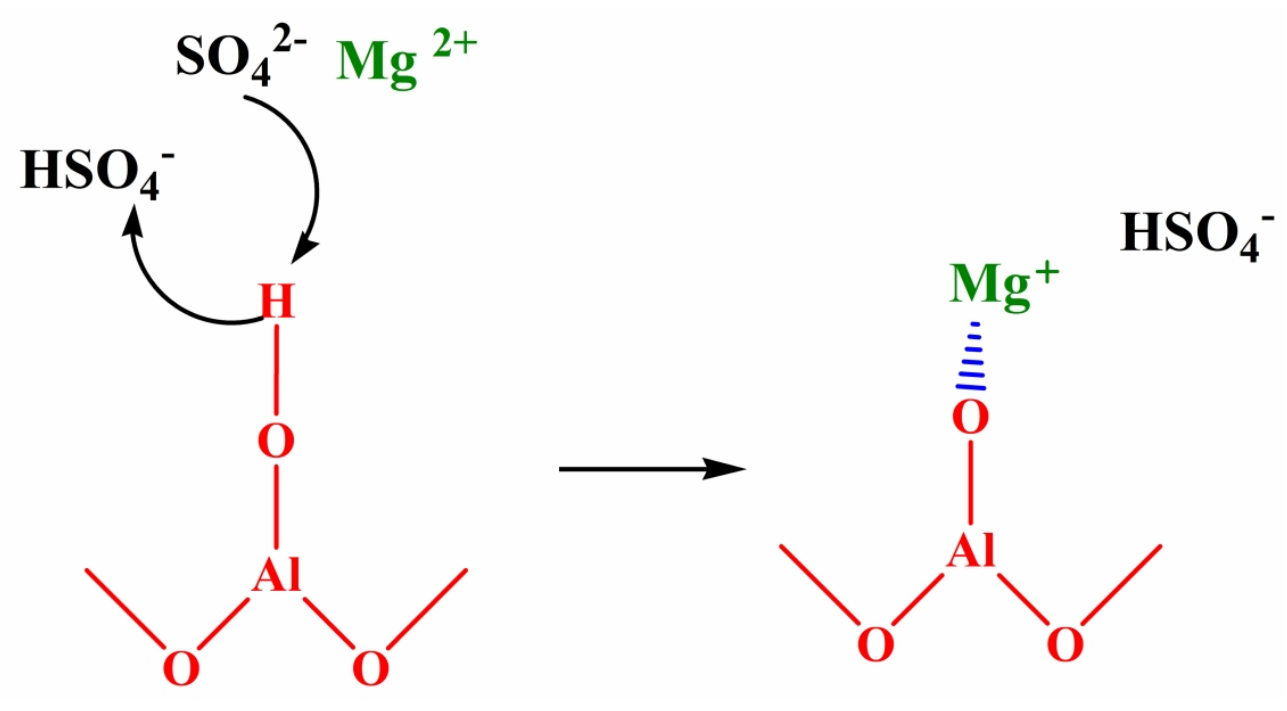

Scheme 1.

$287 \times 152 \mathrm{~mm}(300 \times 300$ DPI $)$ 


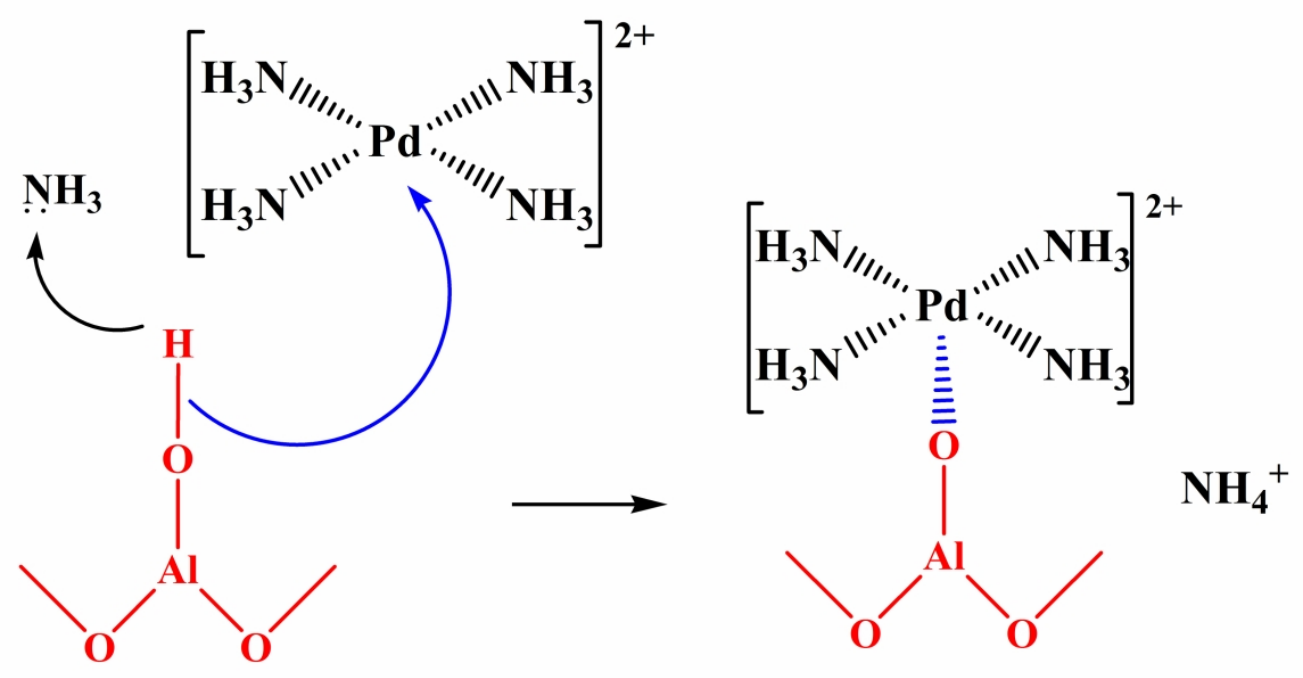

Scheme 2.

$287 \times 152 \mathrm{~mm}$ ( $300 \times 300$ DPI) 

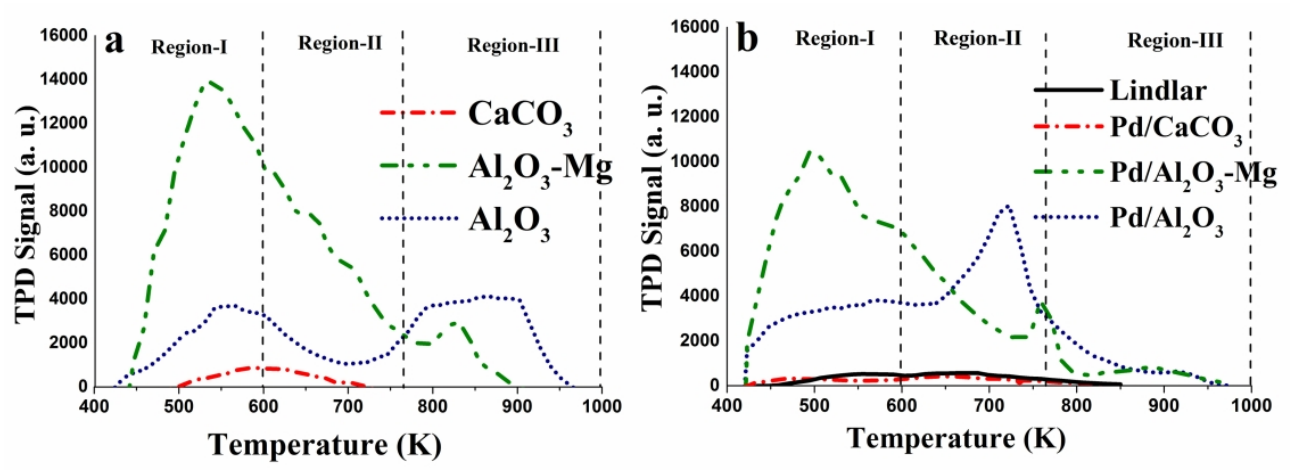

Figure 1.

$304 \times 109 \mathrm{~mm}(300 \times 300$ DPI) 


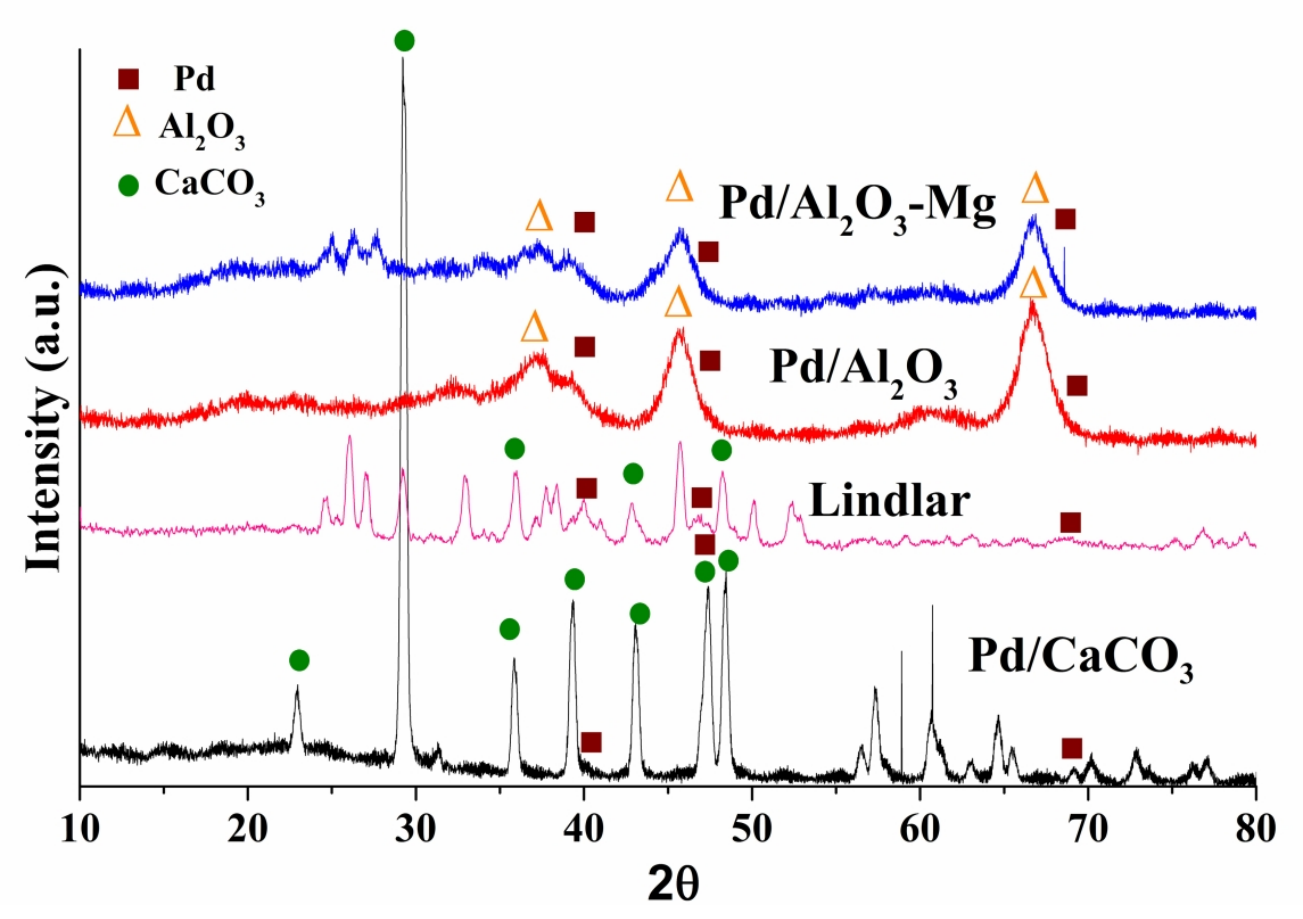

Figure 5.

$286 \times 201 \mathrm{~mm}(300 \times 300$ DPI) 

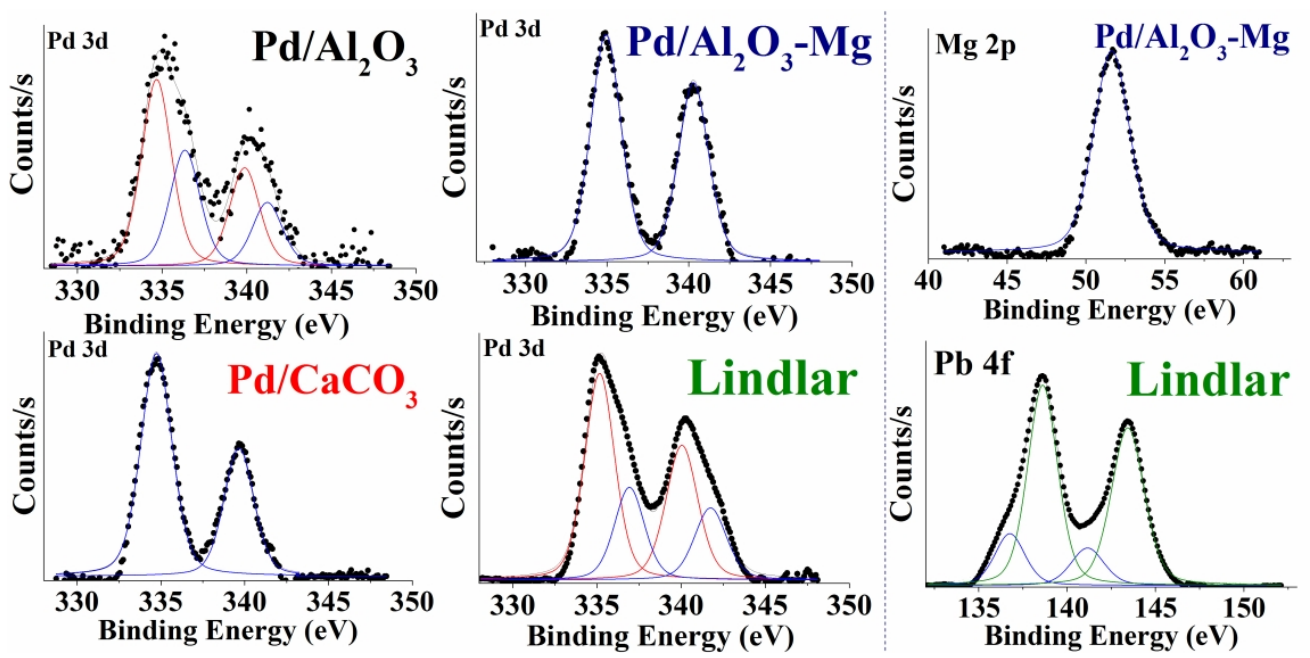

Figura 4.

$406 \times 201 \mathrm{~mm}(300 \times 300$ DPI $)$ 
(b)

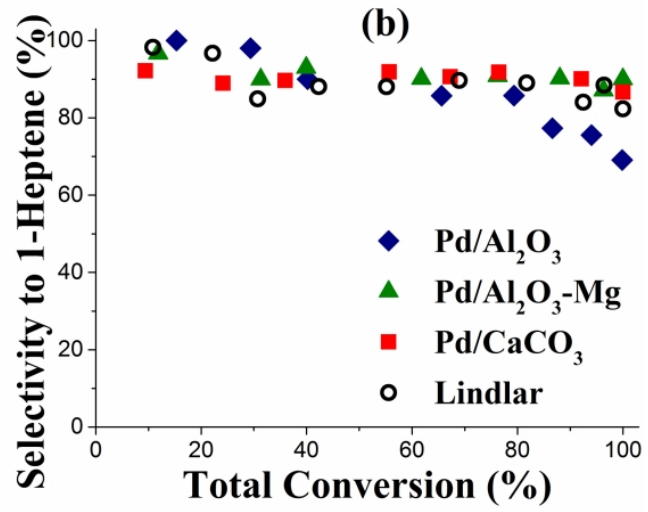

Figure 6 

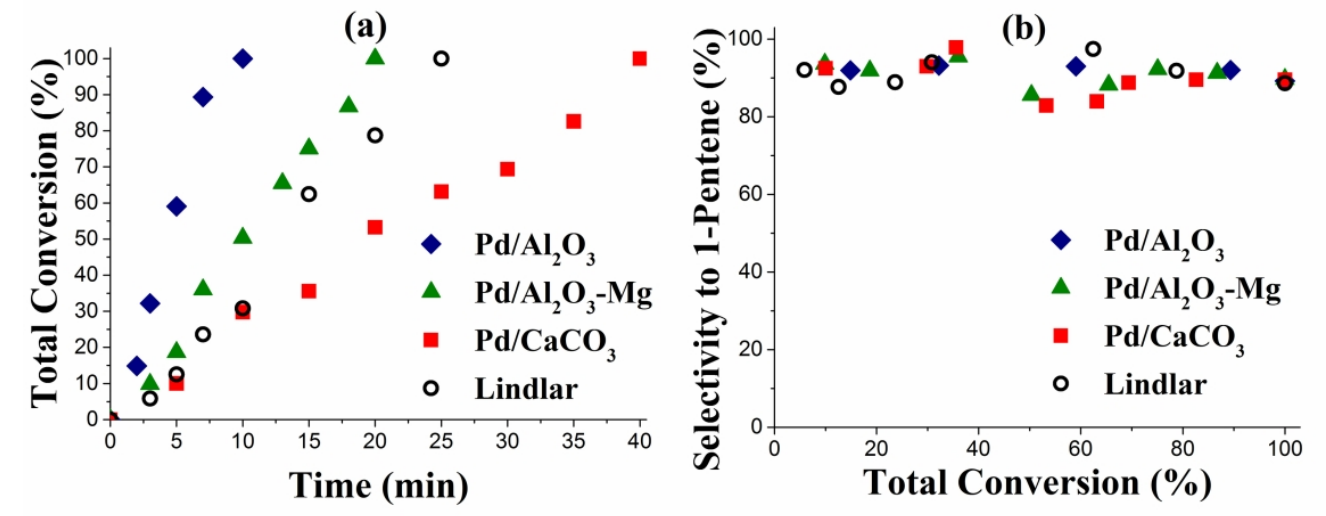

Figure 7

$279 \times 114 \mathrm{~mm}(300 \times 300$ DPI $)$ 

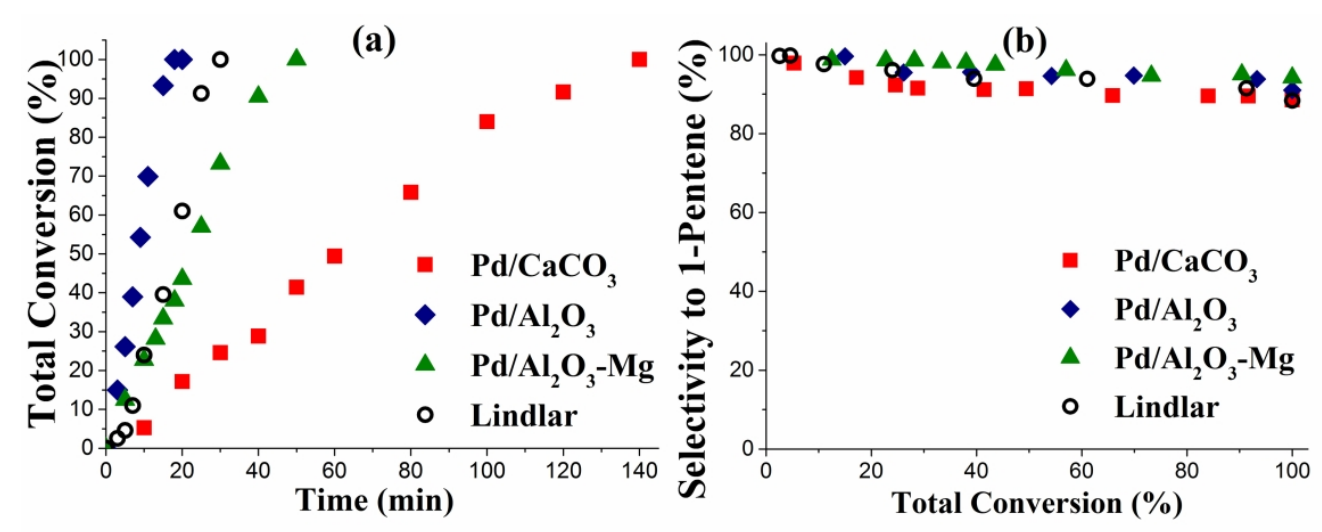

Figure 8

$279 \times 114 \mathrm{~mm}(300 \times 300$ DPI $)$ 

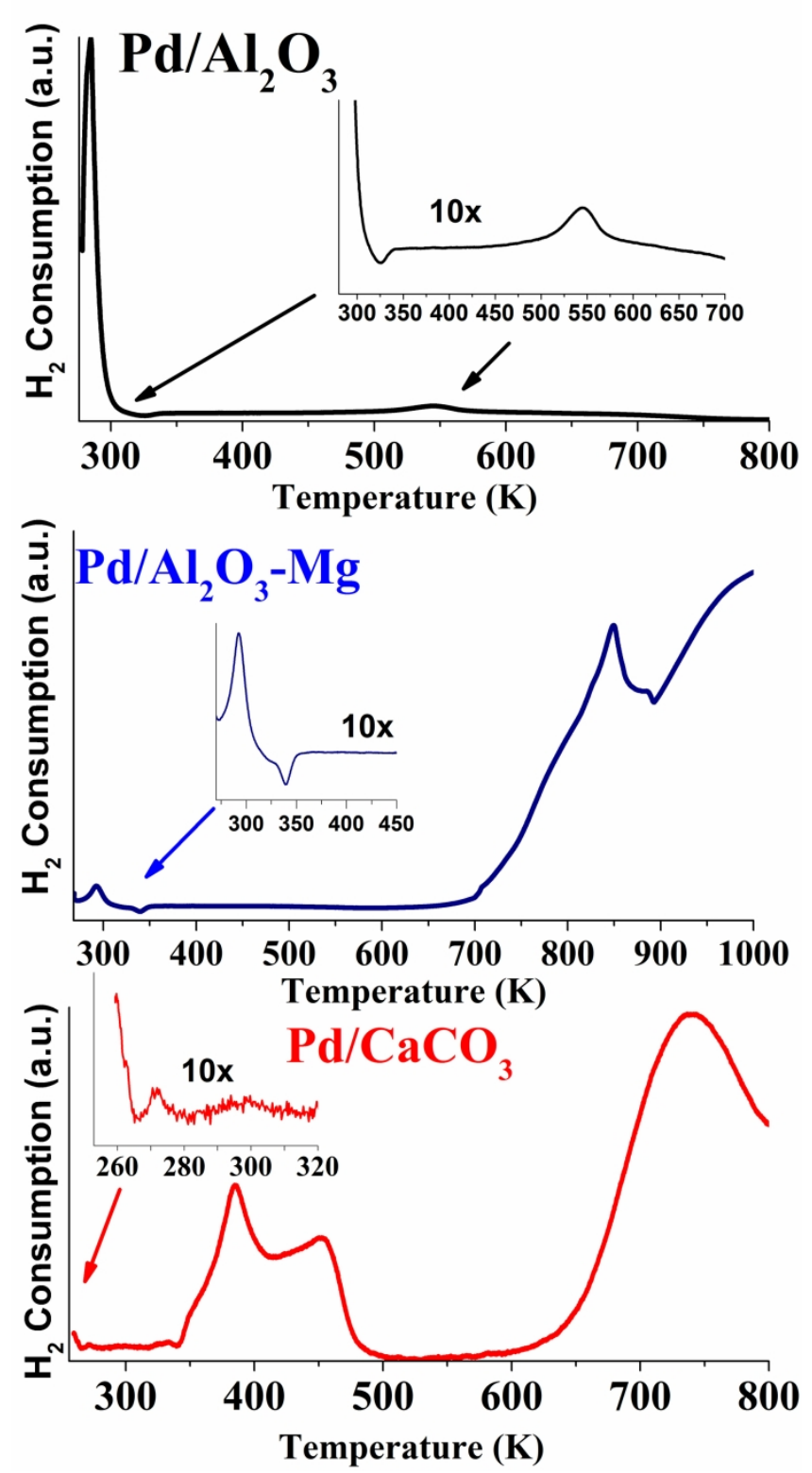

Figure 3.

$149 \times 279 \mathrm{~mm}(300 \times 300 \mathrm{DPI})$ 